\title{
Evaluation of Metalworking Fluid Exposure, Dermatitis, Respiratory Symptoms, and Psychosocial Factors in an Engine Machining Plant
}

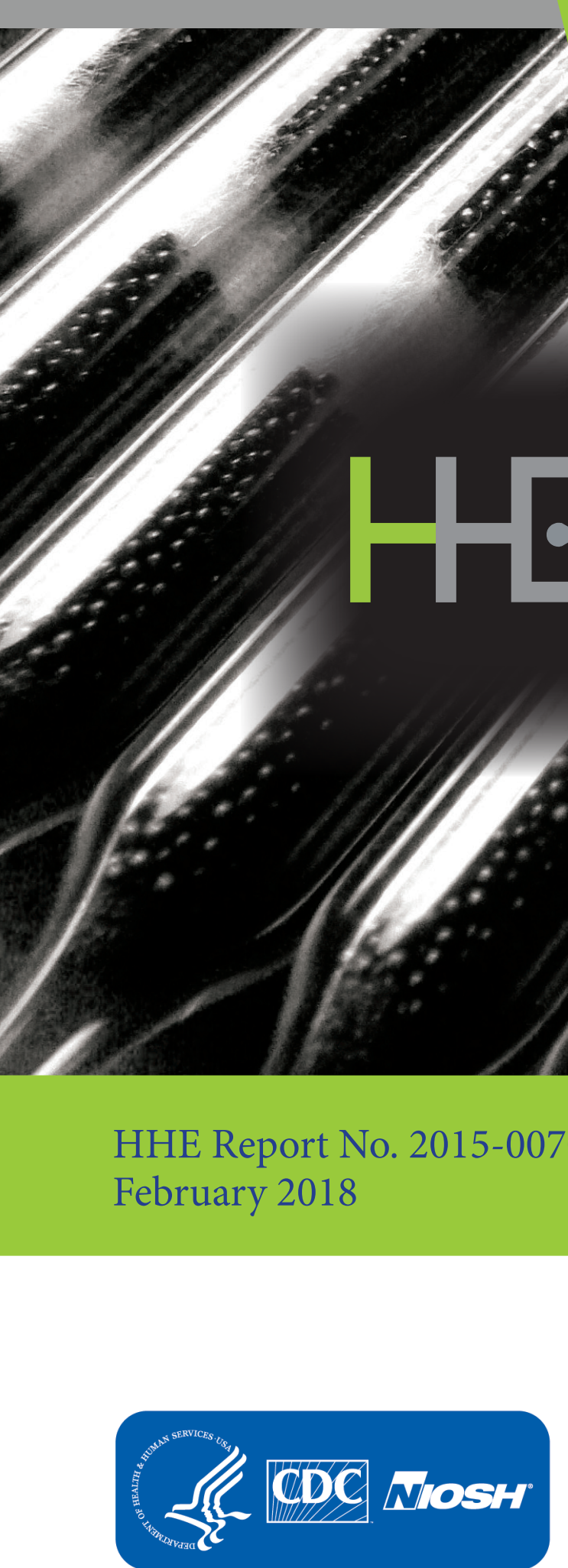

Catherine Beaucham, MPH, CIH Loren Tapp, MD, MS Douglas Wiegand, PhD James Couch, PhD, MS, CIH, CSP, REHS/RS Charles Mueller, MS

HHE Report No. 2015-0070-3304

HealthHazard Evaluation Program 


\section{Contents}

Highlights.

Abbreviations ...................................... iii

Introduction ............................................ 1

Methods ............................................. 2

Results ................................................ 4

Discussion ............................................. 29

Conclusions....................................... 33

Recommendations........................... 33

Appendix A ....................................... 37

Appendix B .......................................... 38

Appendix C ........................................ 40

Appendix D ........................................... 43

References ...................................... 46

Acknowledgements............................ 53

The employer is required to post a copy of this report for 30 days at or near the workplace(s) of affected employees. The employer must take steps to ensure that the posted report is not altered, defaced, or covered by other material.

The cover photo is a close-up image of sorbent tubes, which are used by the HHE Program to measure airborne exposures. This photo is an artistic representation that may not be related to this Health Hazard Evaluation. Photo by NIOSH. 


\section{Highlights of this Evaluation}

The Health Hazard Evaluation Program received a union request from an automotive engine machining plant. The union representative was concerned about respiratory symptoms and skin irritation among cylinder head employees who were exposed to metalworking fluids. We visited the plant in August 2015 and February 2016.

\section{What We Did}

- We observed work practices and personal protective equipment use.

- We reviewed illness and injury logs, air sampling reports, and medical records.

- We interviewed 89 cylinder head employees about their health concerns and examined those with skin rashes.

- We took personal and area air samples for metalworking fluids and area air samples for amines, including dicyclohexylamine (DCHA).

- We administered 172 questionnaires to cylinder head, crankshaft, and long block assembly department employees about their work exposures and symptoms.

\section{What We Found}

- No personal air samples exceeded the occupational exposure limit for metalworking fluid exposure.

- Our short-term area air measurements for DCHA showed that it was present in the plant. No occupational exposure limits exist for this compound and we cannot directly compare area air samples to personal air samples.

- Some metalworking fluid was passing through the mist collectors and being exhausted back into the plant.

We evaluated exposure to metalworking fluids among employees at an engine machining plant. Despite airborne metalworking fluid concentrations being below occupational exposure limits, employees reported respiratory and nasal symptoms. These symptoms were related to the use of compressed air, water, or coolant spray. Employees reported job stress related to air quality and health concerns. We recommend limiting exposure to metalworking fluids by not using compressed air, water, or coolant spray and improving engineering controls, using gloves consistently, improving communication, and encouraging employees to report work-related symptoms early.

- Employees did not use personal protective equipment consistently in areas of the plant that required it.

- Employees in all three departments reported respiratory and skin symptoms related to work, even after DCHA was no longer added to metalworking fluids.

- Respiratory and nasal symptoms were associated with the use of compressed air, water spray, and coolant spray. 
- Seventy-five percent (12 out of 16) employees with rash who were examined at interview appeared to have skin symptoms likely related to coolant exposure.

- Employees reported moderate job stress overall, mainly pertaining to poor air quality and machines not functioning or not being maintained properly.

\section{What the Employer Can Do}

- Modify the machines and work practices to avoid using compressed air, water, or metalworking fluids (coolant spray) to remove metal shavings inside machining equipment or to clean machined parts. Until these modifications are implemented, provide longer tools to dislodge metal shavings and require respiratory and skin protection when using air or sprays.

- Consult the mist collector manufacturer for guidance on preventing the exhaust air from bypassing the filters.

- Extend the mist collector ductwork and exhaust air to the roof or improve the supply airflow throughout the floor levels of the cylinder head line by further extending the ductwork of the heating, ventilation, and air-conditioning system or by redesigning the system so that supply air is introduced at the floor level.

- Train employees on the proper handling and use of metalworking fluids and additives and on the hazards and possible health effects of metalworking fluid exposure.

- Use clear, 2-way communication methods between employer and employees with clear goals. Encourage feedback.

\section{What Employees Can Do}

- Use gloves to avoid skin contact with metalworking fluids.

- Do not wash hands with solvent.

- Wash skin with soap and water if metalworking fluid gets on your skin.

- Report work-related health concerns to your supervisor so steps can be taken to evaluate and control exposures.

- Use clear, 2-way communication methods with the employer and union. Give and receive feedback.

- Seek evaluation from a health care provider if you have symptoms to determine workrelatedness, preventive measures, and care. 


\section{Abbreviations}

ACGIH® $\quad$ American Conference of Governmental Industrial Hygienists

CFR Code of Federal Regulations

DCHA Dicyclohexylamine

DEA Diethanolamine

fpm Feet per minute

GSD Geometric standard deviation

$\mathrm{mg} / \mathrm{m}^{3} \quad$ Milligrams per cubic meter

$\mathrm{mL} \quad$ Milliliter

MEA Monoethanolamine

MWF Metalworking fluid

NIOSH National Institute for Occupational Safety and Health

OEL Occupational exposure limit

OSHA Occupational Safety and Health Administration

PEL Permissible exposure limit

PPE Personal protective equipment

ppm Parts per million

REL Recommended exposure limit

TEA Triethanolamine

TLV® Threshold limit value

TWA Time-weighted average 
This page left intentionally blank 


\section{Introduction}

The Health Hazard Evaluation Program received a request from a union representative at an automotive engine machining plant. The union was concerned about metalworking fluid (MWF) exposures in the cylinder head machining department possibly causing skin and respiratory symptoms among employees. We visited the plant in August 2015 and February 2016 to learn more about these health concerns. We sent summary letters with preliminary recommendations in September and October 2015 and in March and April 2016.

\section{Background}

The requestor and managers reported that south plant employees had begun reporting rashes and respiratory irritation in 2009 that they believed were caused by exposures to an unknown chemical or substance in the rough end of the cylinder headline. A MWF additive called dicyclohexylamine (DCHA) was suspected by the union as possibly being responsible for the reported employee health effects.

\section{Process Description}

About 1,500 employees produced aluminum block automotive engines and cast iron crankshafts. The older north plant opened in the early 1950s while the south plant started production around 2007. Although both plants performed similar machining and assembly operations, the south plant was more automated, using robots and conveyors to transfer the engine parts through manufacturing and assembly. The south plant was the area of concern by the union and the focus of this evaluation.

The south plant had three machining departments (engine block, crankshaft, and cylinder head) and each of these departments were divided into a rough end and the finished end. The cylinder head department was further divided into an A side and a B side (called Headline A and Headline B) that corresponded to the two sides of the engine cylinder head. The south plant also had three assembly departments (head assembly, short block assembly, and long block assembly).

\section{Building Ventilation}

The heating, ventilation, and air-conditioning system in the south plant was a computercontrolled forced-air system with central air conditioning. It was designed to introduce outdoor air from the south side of the plant (assembly) and move it north (machining, including the rough end of the cylinder headline). An air plenum at the bottom of each of the 27 roof-mounted air handling units allowed for return air to be drawn into the system. During our first site visit, each unit was supplying air to the work area in a ratio of $30 \%$ outdoor air and $70 \%$ recirculated air. Each unit had an air filter rated with a minimum efficiency reporting value of 8 . Appendix A, Figure A1 provides a floor plan diagram of the south plant. The filter change out schedule was based on time in service and pressure drop across the filter that is measured using a magnehelic gauge. 


\section{Metalworking Fluid and Mist Collectors}

In August 2015, Quakeral ${ }^{\circledR ~ 481, ~ a ~ s o l u b l e ~(e m u l s i f i e d) ~ M W F ~ t h a t ~ c o n t a i n e d ~ a p p r o x i m a t e l y ~}$ $55 \%-75 \%$ mineral oil, was used in the engine block and cylinder headline machining departments. In February 2016, the plant switched to Quakeral 490 DF, a similar soluble MWF, in the cylinder headline. During both of our site visits, the crankshaft department used Quakercool ${ }^{\circledR} 3511$ BF, a semi-synthetic MWF. No MWFs were used in the assembly departments. Employees in all departments commonly referred to any of the MWFs as coolant.

Twenty-three spiral tube type oil mist collectors operated in the south plant. Each collector was attached via ductwork to between one and five metal-working machines. The air in the mist collectors passed through oil mist filters and then returned to the plant. The collected MWF was cleaned and recirculated through a central system on the west side of the plant and all MWF fluids were managed by a chemicals team contracted by the plant. The MWF maintenance and testing was done either daily, weekly, monthly, quarterly, or yearly depending on the preventive maintenance requirements. Testing included $\mathrm{pH}$, temperature, bacteria, tramp oils, daily dissolved oxygen, fungi, concentration, and endotoxins. Biocides, corrosion inhibitors, and defoaming agents were added as needed.

\section{Methods}

The objectives of this evaluation were to:

1. Characterize employee exposures to MWF mist and amine-based MWF additives, including DCHA.

2. Observe changes made to the general ventilation system and evaluate the mist collectors.

3. Assess the prevalence of and factors related to work-related dermatitis and respiratory symptoms among cylinder head employees.

4. Assess employee perceptions of job stress, effectiveness of workplace controls, and how safety and health issues were addressed by the employer and the union.

\section{Document Review and Workplace Observations}

We reviewed the results from prior industrial hygiene evaluations, safety data sheets for the MWFs, the MWF management system and plan, the general ventilation system, and the operation and maintenance records for the mist collectors, and we observed employees working throughout the plant. We reviewed the company's Occupational Safety and Health Administration's (OSHA) Form 300 Log of Work-Related Injuries and Illnesses for years 2012 through 2015. We requested employee medical records if an employee reported being medically evaluated for a skin or respiratory problem during interviews. We later requested company medical records related to visits for skin and respiratory disorders of employees working in the cylinder head department between January 1, 2012, and September 9, 2015. 


\section{Bulk Metalworking Fluid Sampling}

During our August 2015 visit, we collected and analyzed seven bulk MWF samples for DCHA, diethanolamine (DEA), monoethanolamine (MEA), and triethanolamine (TEA), all common additives to MWFs. During our second visit in February 2016 we collected six additional bulk MWF samples because the plant had changed MWF formulations used in the cylinder head department. We collected approximately 30 milliliters (mL) of the MWFs for each bulk sample. The laboratory analyzed the samples via mass spectrometry according to an internal National Institute for Occupational Safety and Health (NIOSH) method.

\section{Air Sampling}

During both visits we collected area air samples using thermal desorption tubes. We qualitatively analyzed these samples by gas chromatography-mass spectrometry to identify volatile organic compounds such as DCHA, DEA, MEA, and TEA. We also collected 16 area air samples on silica gel sorbent tubes to quantitate the airborne concentration of DCHA using a gas chromatograph/ nitrogen phosphorus detector according to a method developed by Bureau Veritas North America, now known as Maxxam Analytics. This method has not been fully validated.

During our February 2016 visit, we collected 61 personal air samples that were analyzed for total particulate and then extracted for MWF according to NIOSH Manual of Analytical Method 5524 [NIOSH 2018]. Employees were grouped on the basis of where they worked on the days they were sampled: crankshaft machining $(\mathrm{n}=16)$, cylinder headline rough and finished $(\mathrm{n}=29)$, and long block assembly $(\mathrm{n}=16)$.

\section{Ventilation Assessment}

We observed changes made to the general ventilation system and to the mist collectors between our first and second site visits and made general observations in the cylinder head machining department. We randomly selected two of the 23 mist collectors to evaluate the exhaust rate using a VelociCalc ${ }^{\circledR}$ Plus anemometer. For face velocity measurements we visually divided the exhaust hood face into nine equally sized smaller rectangles and measured the air velocity at the center of each rectangle. We then calculated the exhaust flowrate by multiplying the 6.4-square-foot exhaust hood face area with the 2,380 feet per minute (fpm) average face velocity. We used a Fluke ${ }^{\circledR}$ thermal camera to determine if exhaust air was escaping the mist collector prior to filtration.

\section{Medical Interviews and Questionnaires}

In August 2015, we invited all cylinder head employees, some contracted maintenance employees, and those who had previously worked in the cylinder head department for medical interviews. We asked employees about exposures, medical history, and symptoms related to work. We examined their skin if they reported having a current rash. We asked about job stress, perceived effectiveness of workplace controls, and how safety and health issues were addressed by the employer and the union. 
In February 2016, using a questionnaire, we asked all cylinder head line, crank line, and long block assembly line employees about: (1) demographics; (2) work and medical history; (3) personal protective equipment (PPE) use; (4) hygiene habits; (5) exposures outside work; and (6) perceptions of air quality, and communication and trust in their employer regarding safety and health. The questionnaire included asthma questions modified from the European Community Respiratory Health Survey [Grassi et al. 2003] and questions modified from the Nordic Occupational Skin Questionnaire [Susitaival et al. 2003]. We asked about skin, nasal, and respiratory symptoms in the month prior to the questionnaire, and whether these symptoms improved, stayed the same, or worsened on days away from work, on days off, or on vacation. Symptoms that improved on days away from work, on days off, or on vacation were defined as work-related symptoms. The term "coolant" was used instead of "metalworking fluid" in the questionnaire questions because employees referred to MWF as coolant.

Using the questionnaire data, we created a variable that we called "asthma-like symptoms." This variable was designed to identify people who have asthma-like symptoms, but may not have been diagnosed as having asthma [Grassi et al. 2003]. However, our questionnaire asked about symptoms experienced in the prior month, not in the last 12 months (as in the Grassi et al. paper) to assess whether employees continued to have symptoms after the company's changes to the ventilation. We also created a variable called "work-related asthma-like symptoms." Work-related asthma-like symptoms were defined as any of the asthma-like symptoms that were reported to improve when away from work, on days off, or when on vacation. Additional information about these definitions and our data analysis are given in Appendix B.

\section{Results}

\section{Document Review and Workplace Observations}

\section{Prior Industrial Hygiene Evaluations}

The health concerns reported by employees in 2009 prompted the company to conduct a series of industrial hygiene investigations. These investigations were performed by company officials or consultants and occurred between 2010 and 2015 (Table 1). These investigations included microbiological sampling of bulk MWF for bacteria and fungi; and personal and area air sampling for particulate, oil mist, ammonia, total volatile organic compounds, and amine-based MWF additives such as TEA, cyclohexylamine, and DCHA. Only one sample exceeded an occupational exposure limit (OEL). 
Table 1. Summary of prior industrial hygiene evaluations at the south plant

\begin{tabular}{ll}
\hline Date & \multicolumn{1}{c}{ Sampling } \\
\hline 2010 & $\begin{array}{l}\text { Microbial sampling of MWF in } \\
\text { the crankline, blockline, and } \\
\text { cylinder head line in the } \\
\text { south plant }\end{array}$ \\
$2011 \quad \begin{array}{l}\text { Area and personal air sampling } \\
\text { for MWF (as total particulate) } \\
\text { and oil mist }\end{array}$ \\
$2012 \quad \begin{array}{l}\text { Area and personal air sampling } \\
\text { for MWF (as total particulate), } \\
\text { mineral oil mist, amine-based } \\
\text { MWF additives }\end{array}$
\end{tabular}

2014 Area air samples for MWF (as total particulate) and oil mists

Exposures ranged from not detected to 0.29 milligrams per cubic meter $\left(\mathrm{mg} / \mathrm{m}^{3}\right)$ for total particulate and from not detected to $0.12 \mathrm{mg} / \mathrm{m}^{3}$ for oil mist. The highest exposure was measured on one of the Headline A rough-end employees.

MWF concentrations ranged from not detected to $0.55 \mathrm{mg} / \mathrm{m}^{3}$ and the highest personal exposure was collected on a Headline A rough end operator. This sample exceeded the NIOSH REL of $0.5 \mathrm{mg} / \mathrm{m}^{3}$ for MWF as a total particulate. Oil mist ranged from not detected to $0.18 \mathrm{mg} / \mathrm{m}^{3}$, below the OSHA PEL of $5 \mathrm{mg} / \mathrm{m}^{3}$. TEA was not detected, cyclohexylamine ranged from not detected to 0.015 parts per million (ppm), potassium hydroxide was not detected, and ethylene glycol was $0.71 \mathrm{ppm}$.

Particulate matter concentrations were not detectable. Oil mist concentrations ranged from $0.074-0.11 \mathrm{mg} / \mathrm{m}^{3}$.

2015 Indoor environmental quality assessment for total volatile organic compounds

The consultant noted the presence of DCHA and suggested that reduced airflow in the engine block line, crankshaft line, and cylinder headline could have led to stagnant airflow.

A second consultant collected area air samples at the mist collector discharge for amines

Ethanolamine ranged from $0.20 \mathrm{ppm}$ to $0.92 \mathrm{ppm}$. TEA ranged from $<0.51 \mathrm{ppm}$ to $<0.79 \mathrm{ppm}$ and 2-dibutylaminoethanol ranged $<0.024 \mathrm{ppm}$ to $0.070 \mathrm{ppm}$, In response, the plant attached air filters that contained activated alumina and potassium permanganate onto the exhaust outlets for the mist collectors.

2015 Company officials collected All ammonia measurements were below 2 ppm. ammonia samples using a colorimetric indicator tube during ammonia-like odor events

$\mathrm{PEL}=$ Permissible exposure limit

$\mathrm{REL}=$ Recommended exposure limit 


\section{Health and Safety Related Documents}

Table 2 summarizes the injury and illness entries from the north and south plants' OSHA illness and injury logs from 2012-2015. Lacerations, contusions, and abrasions and musculoskeletal sprains and strains accounted for most entries for each year. The six dermatitis entries were all related to coolant exposure and entered as contact dermatitis. The $\log$ had no entries related to respiratory illness.

Table 2. Injuries and illnesses from the north and south plant in the OSHA Log for 2012-2015

\begin{tabular}{lcccc}
\hline Injury/illness type & 2012 & 2013 & 2014 & 2015 \\
\hline Abrasion/laceration/contusion & 6 & 6 & 13 & 9 \\
Strain/sprain & 4 & 3 & 4 & 6 \\
Fracture/dislocation & 0 & 1 & 5 & 3 \\
Contact dermatitis & 2 & 2 & 0 & 2 \\
Eye foreign body & 1 & 0 & 2 & 1 \\
Hearing loss & 0 & 1 & 2 & 2 \\
Broken tooth & 0 & 0 & 2 & 0 \\
Cellulitis & 0 & 0 & 0 & 2 \\
Other & 1 & 0 & 3 & 2 \\
\hline Total & 14 & 13 & 31 & 27 \\
\hline
\end{tabular}

Four cylinder head employees accounted for the nine first aid entries for respiratory complaints that were recorded in the company's health unit first aid logs from January 1, 2012, to April 13, 2015. No medical evaluation was performed as part of these encounters. These included one entry for "respiratory symptoms" in 2013, three "respiratory symptom" entries on March 5, 2015, and two "respiratory" and three "nasal symptom" entries on March 10, 2015. Strong ammonia-like odors were reported by cylinder head employees on March 5, 2015, and March 10, 2015.

According to the company between January 1, 2012, and September 9, 2015, 53 cylinder head employees were evaluated by the company nurse or doctor 161 times. Three employees were seen only once for nonwork concerns. Of the remaining 50 employees, 27 were seen for skin symptoms and 26 for respiratory symptoms. Sixteen employees were seen for acute symptoms (e.g., throat, nasal, and eye burning, difficulty breathing, headache, dizziness, and/or nausea) related to exposure to coolant or ammonia, and five for skin symptoms that occurred after being splashed with coolant. Some employees were seen for more than one type of symptom. Of these 16 reporting acute symptoms from exposure to coolant and ammonia, 11 occurred in March 2015. Company health unit records indicated that the safety department was notified of these reports.

Of the 27 company health unit encounters for skin symptoms not due to a splash, four were designated as work-related by the company medical provider. Our review found an additional 13 encounters likely to be work-related, based on symptom history and evaluation consistent 
with a work-related pattern. Seven other encounters could not be determined to be workrelated based on missing information in the medical record, and three had skin symptoms not related to work (e.g., skin lesions that resembled a fungal skin infection). Two dermatitis cases that were not caused by work appeared to be aggravated by work exposures.

Of the 26 health encounters for respiratory symptoms not related to the acute symptoms due to coolant or ammonia exposures, five had respiratory symptoms we deemed likely to be work-related on the basis of symptom history and evaluation consistent with a work-related pattern. Thirteen had respiratory symptoms that could not be determined to be work-related (missing information), and eight had respiratory symptoms not related to work based on findings in the medical record (e.g., the employee reported viral or allergy symptoms).

We reviewed private medical provider records for 11 cylinder head employees. Respiratory conditions diagnosed by the employees' private medical providers included three cases of upper respiratory infection, two cases of allergic rhinitis, two cases of chronic persistent sinusitis, one case of asthma, and one case of uvulitis (inflammation of the uvula). Skin conditions among six employees were evaluated, and one employee was seen for neurological symptoms. Some employees were seen for both skin and respiratory symptoms. Two employees with skin and upper respiratory symptoms underwent skin prick testing for environmental allergies; both had results indicating several environmental allergies. No employees had skin patch testing for allergic contact dermatitis.

On the basis of our medical record review, two cases of skin conditions appeared to be aggravated by work exposures, but were not caused by work. One report of upper respiratory symptoms (uvulitis) was possibly work-related. Five cases of respiratory symptoms and three cases of skin symptoms had too little information to make any determination of workrelatedness. Three cases of respiratory symptoms, one case of skin symptoms, and the one case of neurological symptoms were unlikely to be work-related. Private medical provider visits were not meant to establish causation, only to improve or resolve symptoms. For most cases, further evaluation (such as skin-patch testing or specific respiratory challenge testing) would be needed to determine if work exposures were related to employees' symptoms.

\section{Workplace Observations}

The required PPE for each job task was posted on a board in each department (Figure 1). The company did not provide uniforms, but did require employees to wear long sleeves and long pants. However, we observed many employees wearing shorts and sleeveless shirts. We also saw employees with improperly inserted ear plugs and some using earbud headphones instead of hearing protectors in areas where hearing protection was required. One employee reported to us, "As my option, I choose to not wear the PPE." 


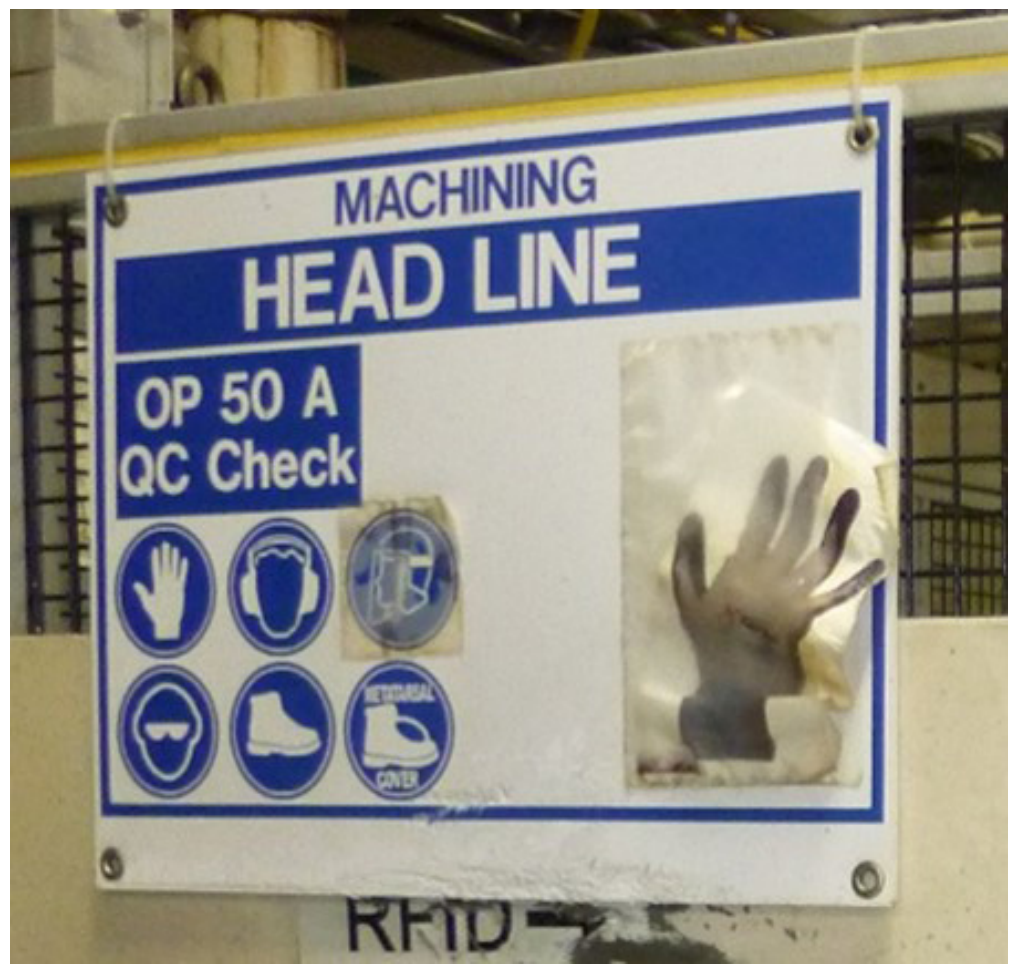

Figure 1. Sign at the quality control check station showing required PPE for the work area. Photo by $\mathrm{NIOSH}$.

We saw employees spraying MWF, water or using a stick to dislodge metal chips inside the equipment they were operating (Figure 2). In all cases the employee turned off the machine and locked out the robot to prevent delivery of parts, but in some situations the employee extended their arms or upper bodies into the equipment to clean it. During cleaning, employees wore one or more of the following: gloves on one or both hands (e.g., nitrile, HyFlex ${ }^{\circledR}$ palmar coated, leather), sleeves (chemical resistant or cotton), glasses (some with side shields, some without), and a face shield. The company did not have a standard operating procedure for dislodging chips. Despite the use of PPE, we saw MWF on employees' skin while performing these tasks. Some employees stated that the oil on their skin did not bother them while others stated they immediately washed the oil from their skin. 


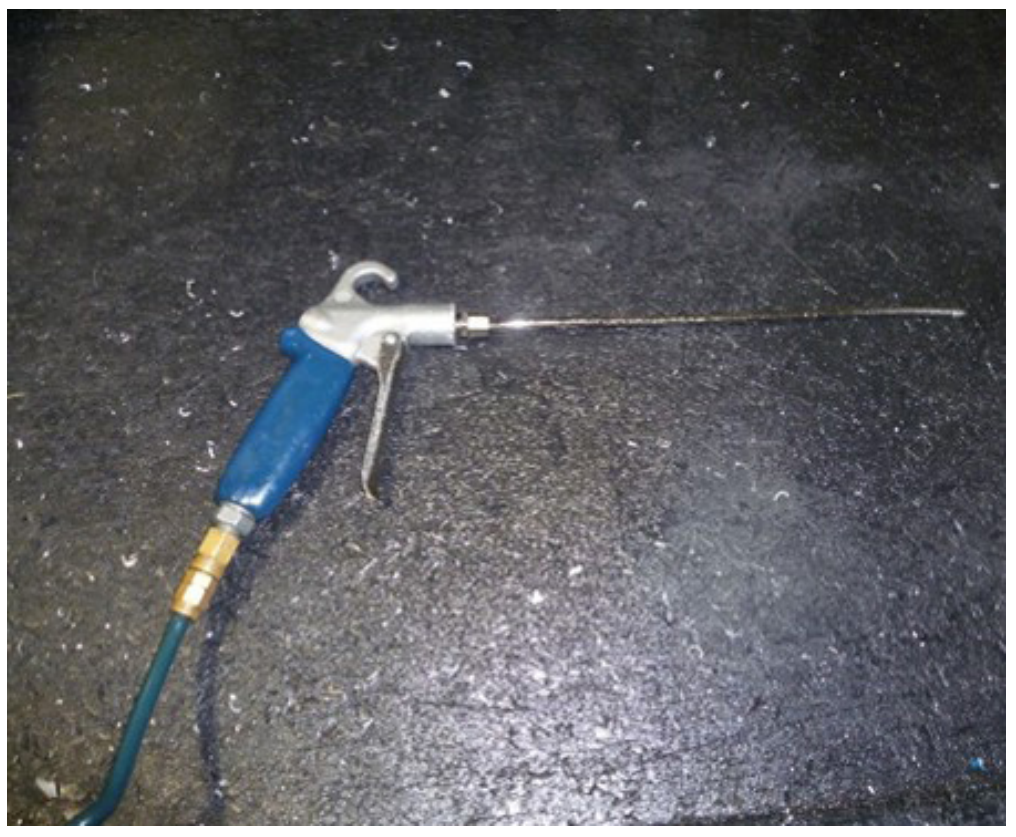

Figure 2. Hand-held MWF spray gun used to dislodge metal chips stuck inside of the machines. Photo by NIOSH.

We observed spilled MWF on the floors outside of the machinery. Some machines had adsorbent floor pads to capture the spilled MWF (Figure 3), but other machines did not.

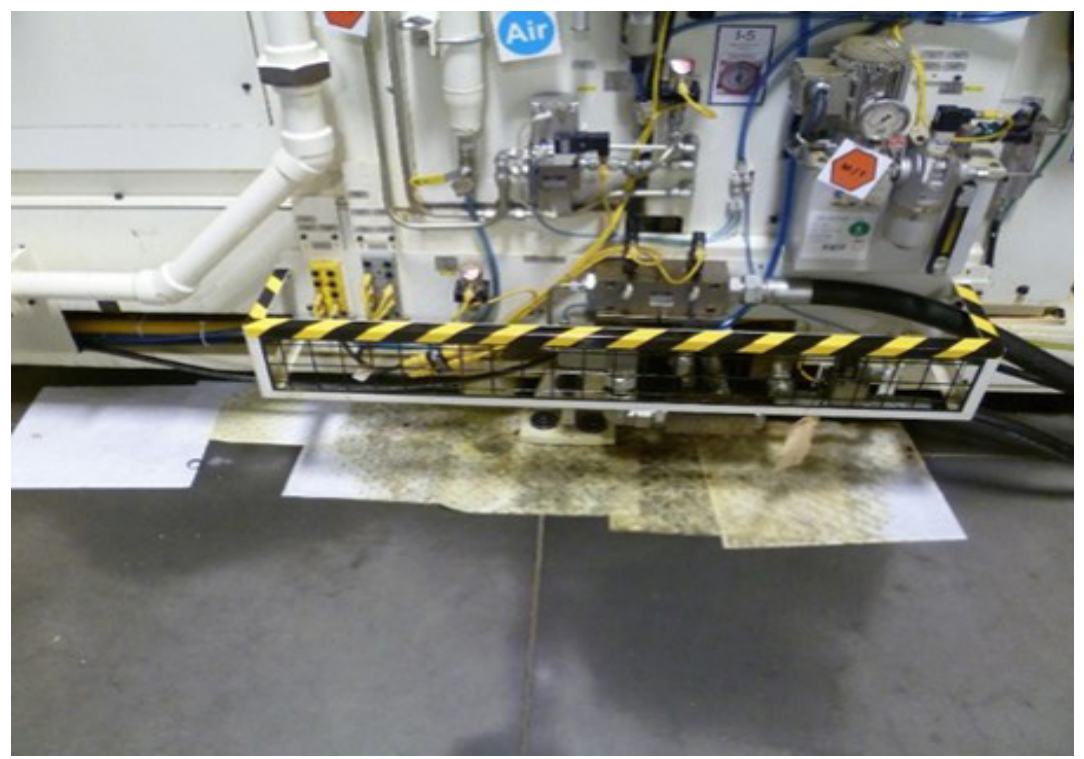

Figure 3. Floor pads beneath machine to absorb spilled MWF. Photo by NIOSH. 
We observed droplets of MWF on the outside of many of the mist collectors, including on the mist collector exhaust grilles (Figure 4) and dripping down the sides of the equipment (Figure 5).

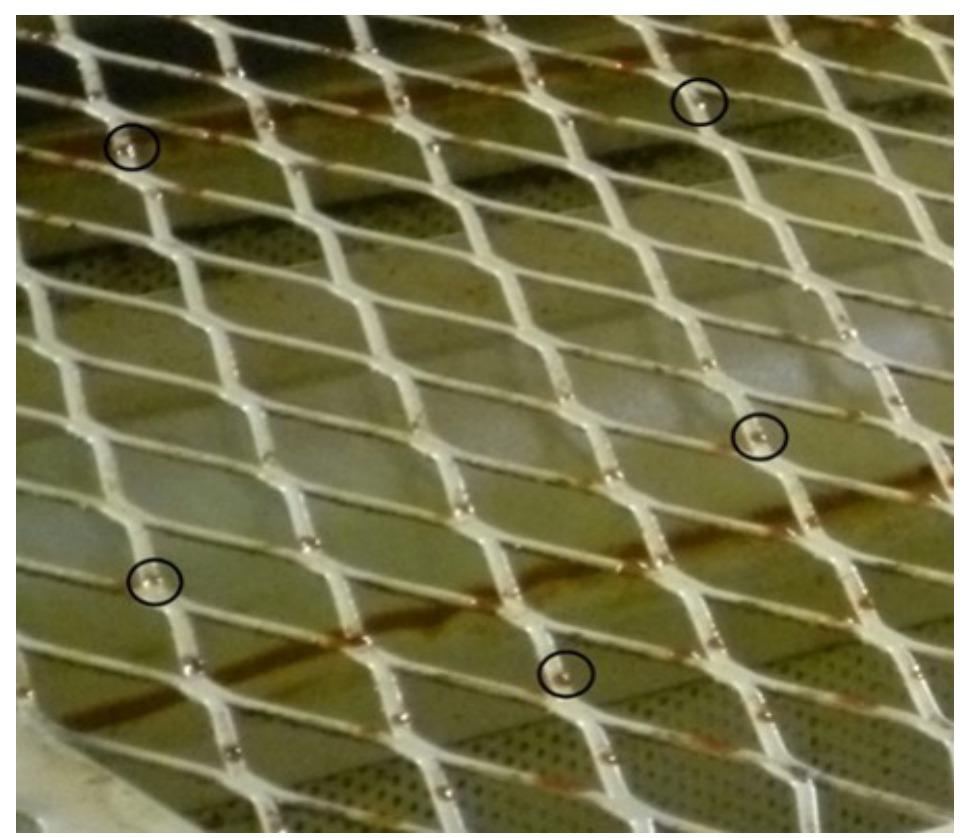

Figure 4. Droplets of MWF on mist collector exhaust grill. Photo by NIOSH.

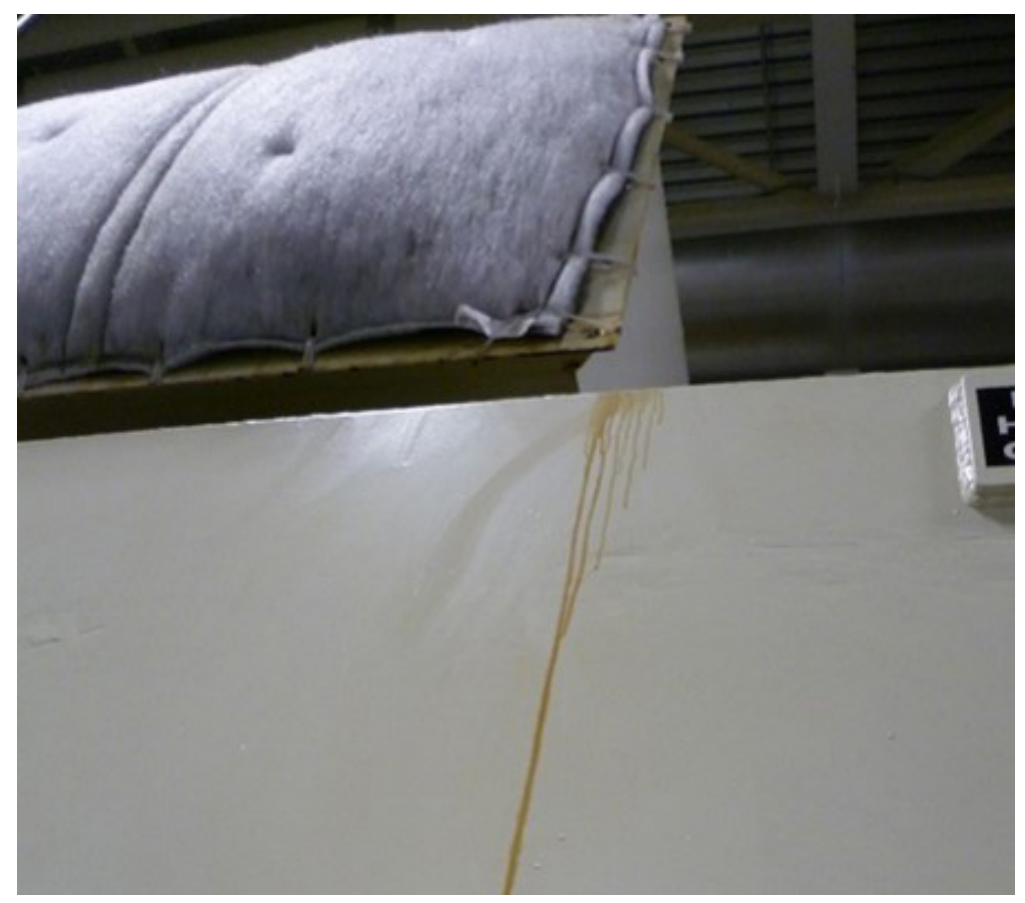

Figure 5. MWF dripping from a mist collector. Photo by NIOSH. 


\section{Bulk Metalworking Fluids}

Table 3 summarizes the predominant amine-based additives present in the bulk MWF samples we analyzed. As expected, DCHA was present in Quakeral 481, but not in Quakercool 3511 BF.

Table 3. Bulk MWF samples collected in August 2015

\begin{tabular}{lcccc}
\hline Type and location of the MWF sample & DCHA & DEA & MEA & TEA \\
\hline Quakeral 481 MWF from cylinder headline & & & & \\
Concentrated (neat) sample: headline main & Yes & No & Yes & Yes \\
Process sample: drip pan in cylinder head machining & Yes & Yes & Yes & Yes \\
Process sample: headline MWF filter gallery & Yes & Yes & Yes & Yes \\
Process sample: headline rough side & Yes & Yes & Yes & Yes \\
Process sample: headline finished side & Yes & Yes & Yes & Yes \\
Quakercool 3511BF from crankshaft machining line & & & & \\
Concentrated (neat) sample: crankline machining & No & No & Yes & Yes \\
Process sample: crankline machining & No & Yes & Yes & Yes \\
\hline
\end{tabular}

Note: neat sample $=$ new (unused) MWF; process sample $=$ used MWF

Table 4 summarizes the analyses of bulk MWF samples we collected in February 2016. The MWF used in the crankshaft area had similar amine-based additives as those found in MWF samples collected in August 2015 except that the process sample contained DCHA. Two unknown amine compounds were present in the highest proportion in all six MWF samples (not shown). TEA was also present in all the samples, but in relatively lower proportions. We found DCHA in slightly greater proportion than TEA in the process sample collected from the headline main. DCHA was also present in the concentrated headline valve seat MWF sample, but in a relatively small proportion. Additional information on DCHA is given in Appendix C.

Table 4. Amines in bulk MWF samples collected in February 2016

\begin{tabular}{lcccc}
\hline Type and location of the sample & DCHA & DEA & MEA & TEA \\
\hline Quakeral 490 DF from cylinder headline & & & & \\
Concentrated sample: headline main & No & Yes & Yes & Yes \\
Process sample: headline main & Yes & Yes & Yes & Yes \\
Concentrated (neat) sample: headline valveseat & Yes & Yes & Yes & Yes \\
Process sample: headline valveseat & Yes & Yes & Yes & Yes \\
Quakercool 3511BF from crankshaft machining & & & & \\
Concentrated (neat) sample: crankline main & No & Yes & Yes & Yes \\
Process sample: crankline main & Yes & Yes & Yes & Yes \\
\hline
\end{tabular}

Note: neat sample $=$ new (unused) MWF; process sample $=$ used MWF 


\section{Air Sampling}

Table 5 shows the results from full-shift personal air sampling in the cylinder headline, crankshaft, and long block assembly lines. None exceeded the NIOSH REL of $0.4 \mathrm{mg} / \mathrm{m}^{3}$ for MWF, measured as thoracic particulate. Using the Wilcoxon rank-sum test to compare concentrations, the MWF concentrations in the cylinder head machining line were not significantly higher than the crankshaft machining department $(P>0.25)$, but were significantly higher than the long block assembly department $(P<0.001)$. For sample results that were not detected, we imputed a value by dividing the minimum detectable concentration $\left(0.02 \mathrm{mg} / \mathrm{m}^{3}\right.$ based on an average sample volume of 1.6 liters $)$ by the square root of 2 [Hornung and Reed 1990]. Additional information on MWF is given in Appendix C.

Table 5. Summary of personal airborne exposures to MWF fluid, in $\mathrm{mg} / \mathrm{m}^{3}$

\begin{tabular}{lcccc}
\hline Location & $\begin{array}{c}\text { Number of } \\
\text { samples }\end{array}$ & $\begin{array}{c}\text { Concentration range } \\
\left(\mathrm{mg} / \mathrm{m}^{3}\right)\end{array}$ & $\begin{array}{c}\text { Geometric mean } \\
\left(\mathrm{mg} / \mathrm{m}^{3}\right)\end{array}$ & GSD \\
\hline Cylinder headline & 28 & {$[0.057]^{*}-0.17$} & 0.099 & 1.292 \\
Crankshaft line & 16 & {$[0.039]-0.17$} & 0.086 & 1.560 \\
Long block assembly line & 16 & ND† to $[0.077]$ & 0.024 & 3.054 \\
\hline NIOSH REL & 0.4 & \\
OSHA PEL & $5 \ddagger$ & \\
ACGIH TLV & None & \\
\hline Minimum Detectable Concentration & 0.02 & \\
Minimum Quantifiable Concentration & 0.08 & \\
\hline GSD = Geometric standard deviation & & \\
TLV = Threshold limit value & \\
& ${ }^{*}$ The values in brackets are between the minimum detectable concentration and the minimum \\
quantifiable concentration, meaning more uncertainty is associated with these concentrations. \\
†Not detected, below the minimum detectable concentration \\
†Measured as respirable particulate
\end{tabular}

The August 2015 results for DCHA are shown in Table 6. Sample times were 187-254 minutes. Although no OELs exist for DCHA in the United States, the Registration, Evaluation, Authorisation, and Restriction of Chemicals legislation developed by the European Union has established a derived no effect level of $0.353 \mathrm{mg} / \mathrm{m}^{3}$, which is defined as the "level of exposure above which humans should not be exposed" [OECD 2015]. Since we collected short-term area samples, we cannot directly compare them with full-shift personal air samples or the derived no effect level. 
Table 6. Results of DCHA area air sampling collected in

August 2015

\begin{tabular}{lc}
\hline Location & $\begin{array}{c}\text { Concentration } \\
\left(\mathrm{mg} / \mathrm{m}^{3}\right)\end{array}$ \\
\hline South plant & \\
Cylinder Headline A & 0.24 \\
$\quad$ Finish end, OP 135A on QC desk & 0.24 \\
Finish end, OP 110 A, QC station & 0.14 \\
$\quad$ Rough end, OP 45A by robots & 0.15 \\
$\quad$ Rough end, OP 30 A 6 and 7 & \\
Cylinder Headline B & {$[0.12]^{*}$} \\
$\quad$ Finish end, OP 120B, QC station & Not detected \\
Finish end, OP 140 B on desk & Not detected \\
Rough end, OP 25 B & \\
Other areas & 0.19 \\
OP 55 A rollover, rough A & Not detected \\
OP 45 B rollover blow off, check & \\
station 40 & {$[0.12]$} \\
Dyno area & 0.14 \\
Pumpback, head A, rough (by corner & \\
of concern) & \\
Head filter gallery & Not detected \\
Operators station, rough A Op 20 QC & 0.20 \\
Conference room & Not detected \\
Crankline, OP 60 QC check & Not detected \\
North plant & \\
Rough headline OP 20B1 & 0.07 \\
\hline Minimum detectable concentration \\
Minimum quantifiable concentration
\end{tabular}

*Values in brackets are between the minimum detectable concentration and the minimum quantifiable concentration meaning more uncertainty is associated with these concentrations.

†Below the minimum detectable concentration.

Table 7 shows the results for DCHA in general area air samples collected in February 2016 in the south plant. Sample times ranged from 42 to 122 minutes. We did not detect DEA, MEA, or TEA on any of the 10 thermal desorption samples we collected throughout the crankline, cylinder headline, and long block assembly line. We only detected DCHA in the sample collected at the cylinder Headline B rough end $\left(0.32 \mathrm{mg} / \mathrm{m}^{3}\right)$ and in the sample collected at the crankline rough end $\left(0.58 \mathrm{mg} / \mathrm{m}^{3}\right)$. 
Table 7. Results of DCHA area air sampling collected in February 2016

\begin{tabular}{lc}
\hline Location & $\begin{array}{c}\text { Concentration } \\
\left(\mathrm{mg} / \mathrm{m}^{3}\right)\end{array}$ \\
\hline Cylinder Headline A & \\
Rough end & Not detected \\
Rough end, corner & Not detected \\
Finish end & Not detected \\
Cylinder Headline B & \\
Rough end & 0.32 \\
Finish end & Not detected \\
Crankline & \\
Rough & 0.58 \\
Finish & Sample lost \\
Other areas & \\
Longblock assembly & Not detected \\
Longblock assembly & Not detected \\
Conference room & Not detected \\
\hline Minimum detectable concentration & 0.2 \\
\hline *Below the minimum detectable concentration
\end{tabular}

Analysis of the thermal desorption tubes and area air samples collected in August 2015 identified DCHA with the exception of the sample collected in the conference room. Its primary peak was limonene, which is a chemical commonly found in cleaning products.

\section{Ventilation}

Prior to our first visit, the company had attached air filters containing activated alumina and potassium permanganate onto the mist collector exhausts (Figure 6). The intent was to capture amine or ammonia-like odors that may have been released from the mist collectors. However, the mist collectors were not designed to have filters installed on the exhaust. 


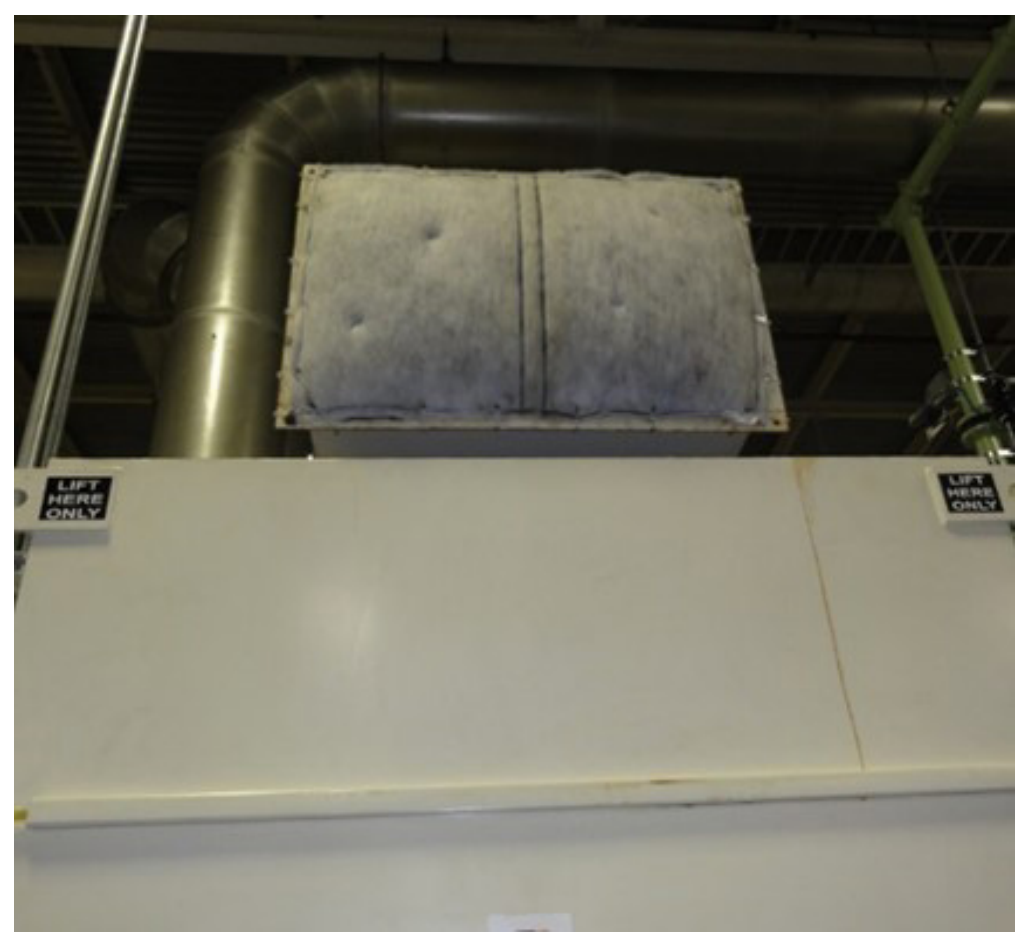

Figure 6. An air filter impregnated with potassium permanganate attached to an exhaust duct from a mist collector. A line of MWF was dripping from the corner of the filter. Photo by NIOSH.

Between our August 2015 and February 2016 site visits, the plant was cited by OSHA for introducing insufficient outdoor air. In January 2016, the facility hired a contractor to identify deficiencies in the ventilation system. The contractor concluded that air exhausting from the building through open roll up doors prevented the ventilation system from working as designed to remove MWF particulate and residual odors. The ventilation system was designed to move air from the floor level and exhaust it at the ceiling through rooftop air handling units. The changes the facility made as a result of the contractor's assessment, the OSHA citation, the indoor environmental quality study, and our first site visit included:

- Increasing the percentage of outdoor air from $45 \%$ to $100 \%$ with no recirculation.

- Extending the air supply ducts by adding a downward facing air supply at the terminal ends of the ducts (Figure 7).

- Removing the filters from the mist collector exhausts.

- Creating a 90-degree turn in the exhaust duct, and extending the exhaust duct up closer to the ceiling (Figure 8). Alternatively, a metal diverter (Figure 9) was attached to help direct the airflow from the mist collector upwards. Some exhaust ducts had nothing attached.

- Replacing the MWF that contained DCHA (Quakeral 481) with one that did not contain DCHA (Quakeral 490 DF) in the cylinder head line. Quakeral 481 continued to be used in the engine block line.

- Installing large industrial fans on the ground level in the cylinder headline to increase air movement through the department. 
Oil mist collectors $\mathrm{H} 2$ and $\mathrm{H} 7$ exhausted horizontally and the face surface area of each was 6.4 square feet. The average air velocity across the face of the $\mathrm{H} 2$ exhaust hood was 2,400 fpm (range: 1,000-5,200 fpm). The calculated H2 mist collector exhaust flowrate was 15,000 cubic feet per minute. The average air velocity across the face of the $\mathrm{H} 7$ exhaust hood face was 2,800 fpm (range: 600-4,000 fpm). The H7 mist collector had an exhaust flowrate of 18,000 cubic feet per minute. Although we did not evaluate the mist collectors with their exhaust directed towards the ceiling or with the deflector pan because we could not reach them, we would expect similar rates. However, additional ductwork to redirect the air towards the ceiling could reduce the flowrate, but the impact would be minimal.

Using the thermal camera, we determined that the exhaust air from the mist collectors was the same temperature as the workplace air. Employees familiar with the exhaust systems had believed that the exhausted air was warmer than the workplace air and that residual MWF in the warm exhaust air was being carried towards the ceiling and away from the work floor. However, this was not the case during our site visit. Because the exhaust and workplace air were similar in temperature, we were unable to use the thermal camera to identify possible exhaust leaks.

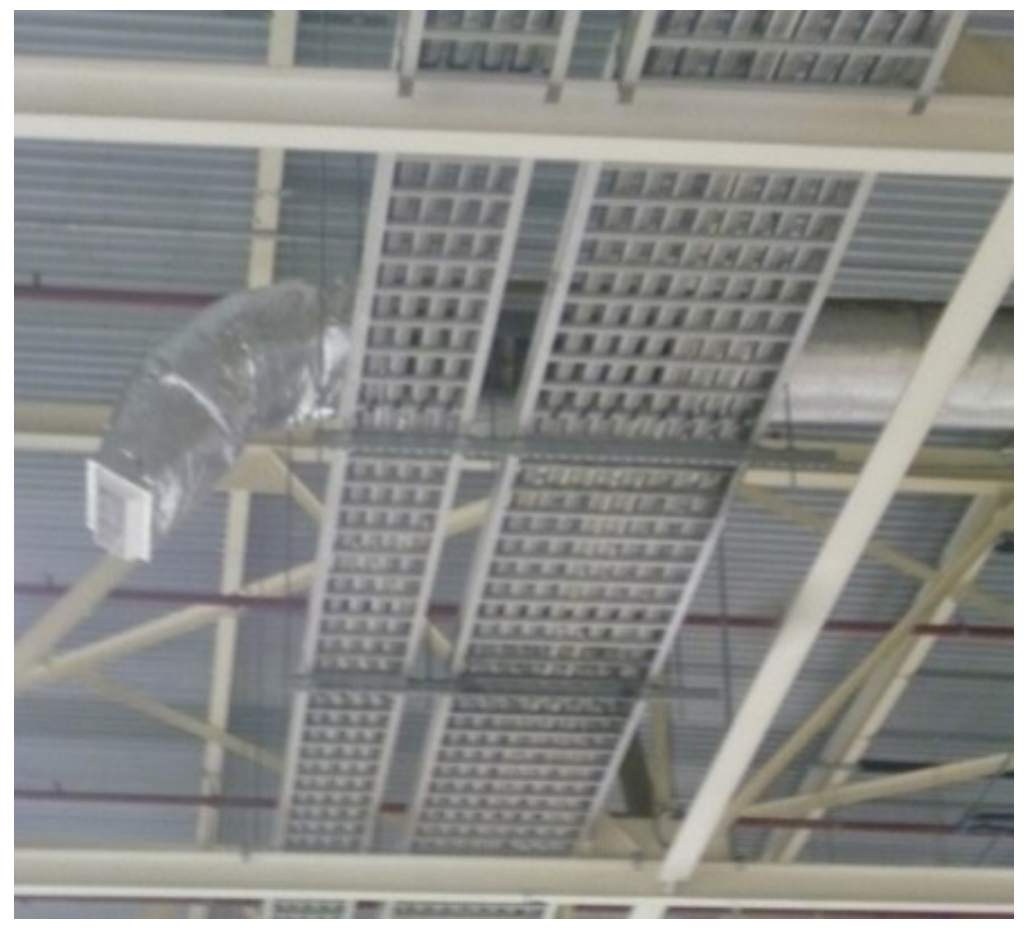

Figure 7. Extension attached to the end of an air supply duct near the ceiling, directed downward to improve air movement. Photo by $\mathrm{NIOSH}$. 


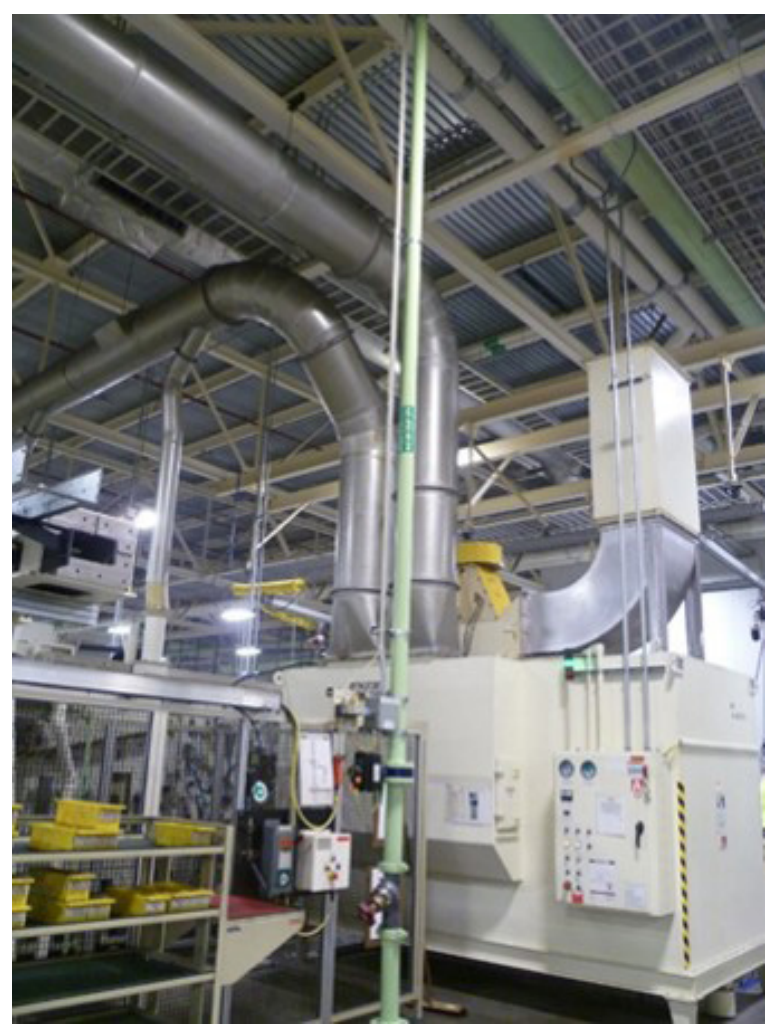

Figure 8. A mist collector exhaust that has been redirected to exhaust closer to the ceiling. Photo by NIOSH.

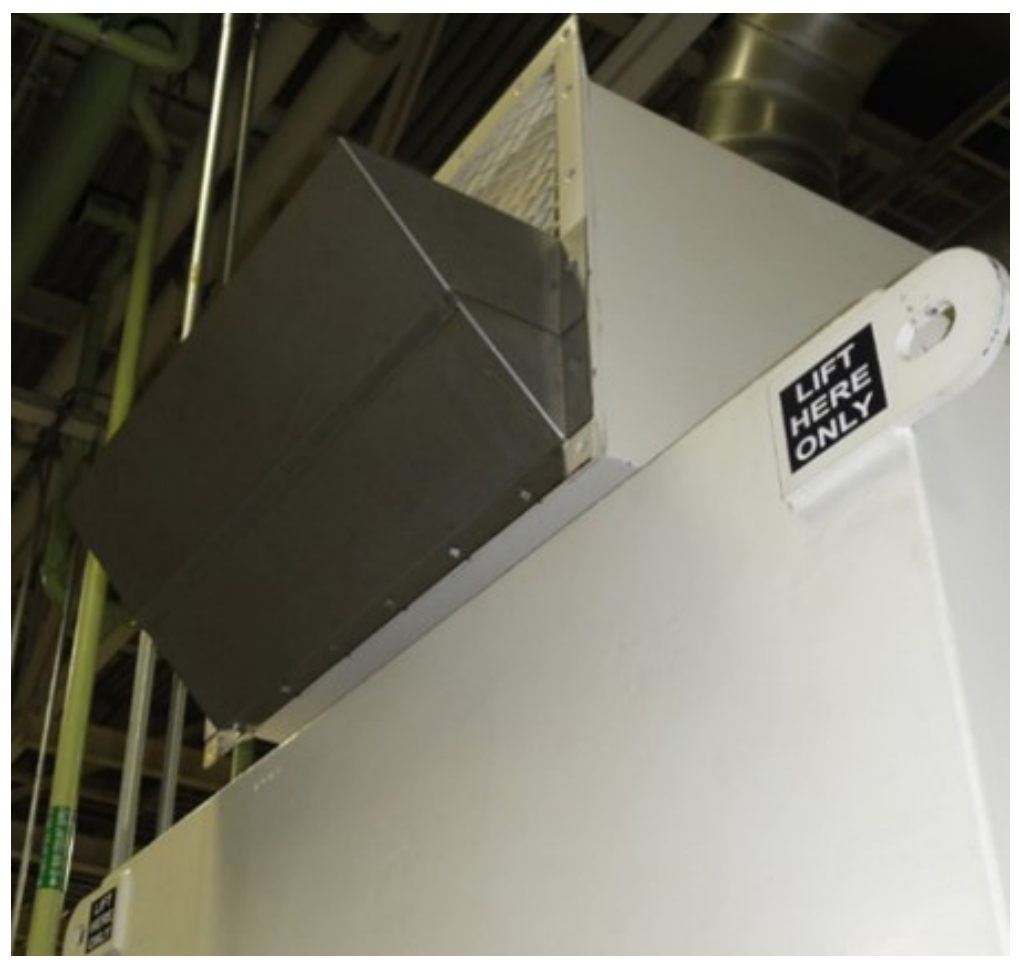

Figure 9. A mist collector exhaust with a metal diverter installed to direct airflow upward. Photo by NIOSH. 


\section{Confidential Medical Interviews}

In August 2015, we held confidential medical interviews with 89 employees, including all 67 working mostly or exclusively in the cylinder head department (the area of concern) at the time of our visit, and 22 working in multiple areas of the south plant or working mostly or exclusively in other departments. Of the 67 employees in cylinder head, 38 were machine operators, 10 team leads, 10 skilled trade, maintenance, or repair employees, 4 technicians, and 5 employees in various other jobs. Of the remaining 22 employees, 7 were skilled trade, maintenance, or repair employees ( 1 in north plant), 5 dyno operators (adjacent to cylinder head department), 3 assemblers ( 2 in the north and 1 in south plant), 3 cutter/grinders, and 4 employees in various other jobs. Of these 22 employees, 7 had previously worked in the cylinder head department.

Of the 89 participants, the average age of the employees was 49 years (range: $23-66$ years), the average duration of employment was 19 years (range: $0.3-39$ years), and the average time in the south plant was 4.2 years (range: $0.3-7$ years). The average number of years worked in their current area was 3 years (range: $0.25-7$ years).

We asked employees if they had ever been diagnosed with certain respiratory illnesses and if they were first diagnosed with the illness before or after being hired for this job. Of 88 participants who answered, 10 reported being diagnosed with sinusitis, 9 with allergies, 7 with bronchitis, 3 with asthma, and 3 with pneumonia all after starting their current job. Sixteen interviewed employees reported smoking in the past, 24 currently smoked, 44 never smoked, and 2 chewed tobacco or smoked cigars.

We asked the 89 employees whether they had specific symptoms in the month prior to our visit. Table 8 shows the type and frequency of symptoms reported and the number of employees who reported that the symptom(s) was better when away from work on days off or when on vacation.

Table 8. Employee reports of symptoms during the month prior to interviews, by symptom type, frequency, and relation to work $(n=89)$

\begin{tabular}{lccc}
\hline Symptom & $\begin{array}{c}\text { No. of employees } \\
\text { reporting symptom } \\
\text { in past month }\end{array}$ & $\begin{array}{c}\text { No. of employees } \\
\text { reporting symptom } \\
\text { occurring more than } \\
\text { once a week }\end{array}$ & $\begin{array}{c}\text { No. of employees } \\
\text { reporting symptom } \\
\text { improves away } \\
\text { from work }\end{array}$ \\
\hline Eye irritation & 62 & 35 & 55 \\
Runny nose & 54 & 37 & 37 \\
Cough & 52 & 33 & 40 \\
Throat irritation & 46 & 33 & 39 \\
Skin irritation & 50 & 29 & 40 \\
(red, dry, bumps) & 40 & 24 & 36 \\
Skin itching & 29 & 18 & 22 \\
Shortness of breath & 29 & 12 & 23 \\
Wheeze & 21 & 10 & 15 \\
Chest tightness & & & \\
\hline
\end{tabular}


Of the 50 employees reporting skin irritation in the past month, 22 employees reported they had a rash on the day of the interviews. We obtained consent to photograph 16 of these employees' rashes; eight had skin lesions on their forearm, four had facial skin irritation or eruptions, and four had hand or finger lesions. On the basis of work and medical histories and physical examinations, 12 of the 16 employees with rash appeared to have contact dermatitis or folliculitis (inflammation of a hair follicle) with a possible work-related component, including skin symptoms related to coolant exposure, and exacerbation of a prior skin condition with coolant exposure. The remaining four employees had skin symptoms that did not appear to be work-related. Photos of two employees' skin lesions are shown in Figure 10 (a rash that is consistent with semiacute dermatitis), and Figure 11 (skin changes consistent with chronic dermatitis).

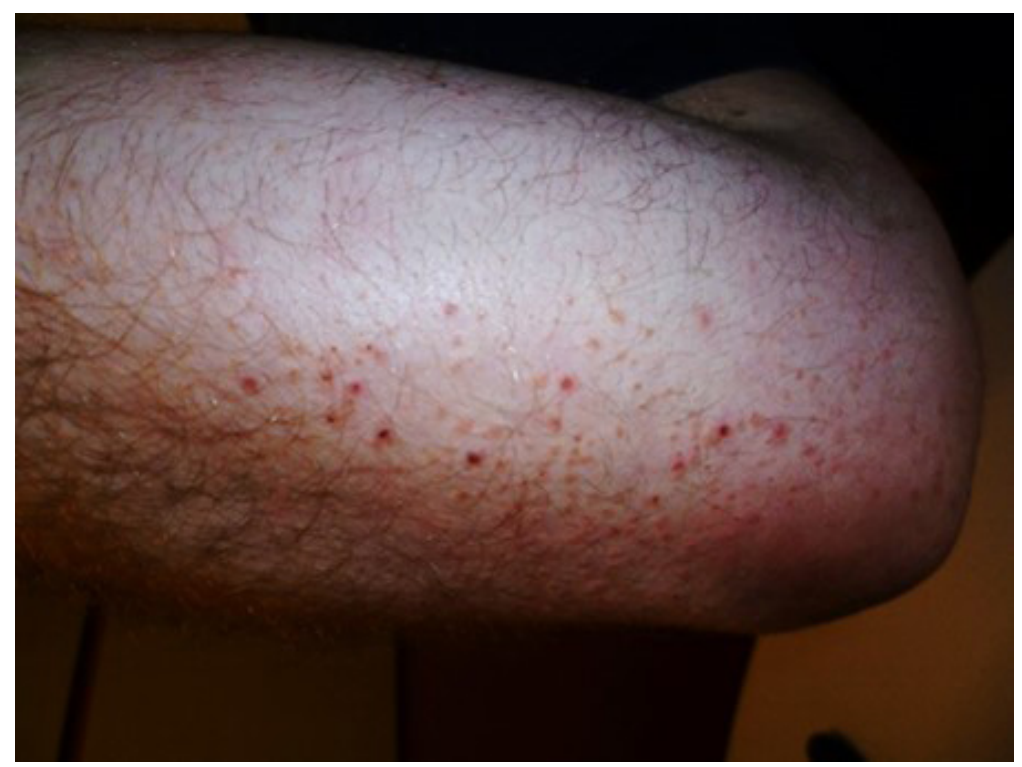

Figure 10. Upper forearm of employee with numerous reddened papules and a few pustules. Photo by $\mathrm{NIOSH}$.

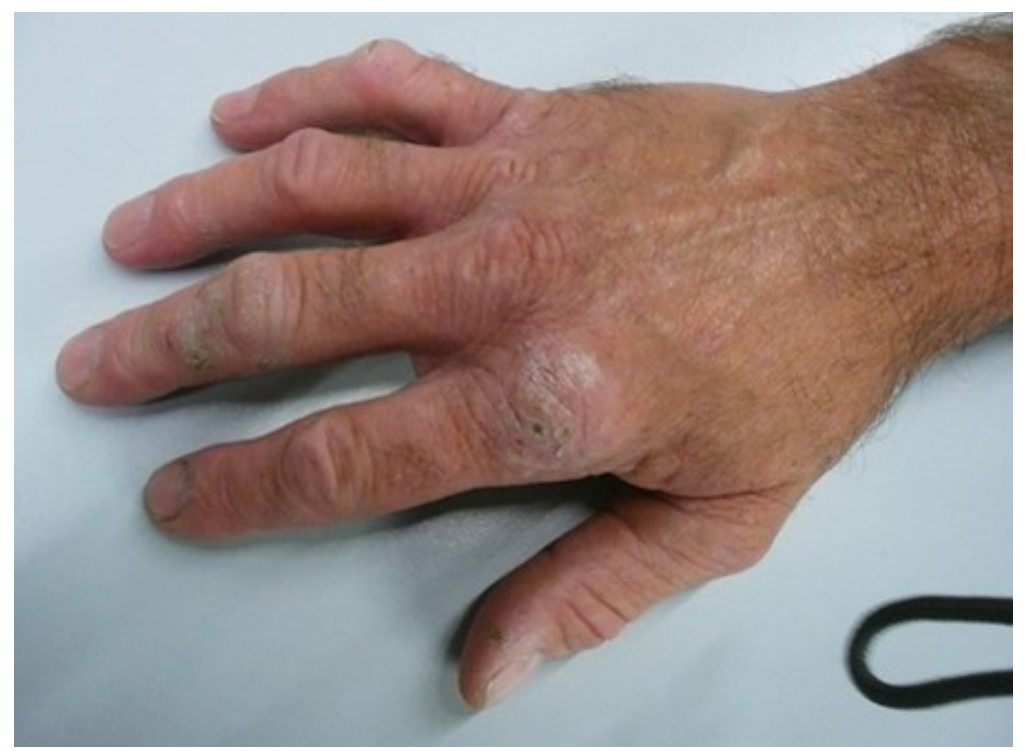

Figure 11. Right hand of an employee with thickened, dry, flaking patches on fingers, knuckles, and thumb. Photo by NIOSH. 
Among the 89 employees, 46 reported seeking medical care for a health problem they thought was work-related; 18 saw the plant doctor, 10 saw the plant nurse, and 37 saw a personal doctor. Some employees saw more than one type of provider. Twelve of these 46 employees reported being seen for nasal/sinus symptoms; 14 for respiratory symptoms (including 5 for asthma, 2 for chronic obstructive pulmonary disease, 1 for pneumonia, and 1 whose respiratory symptoms were related to a heart problem); 12 for skin rash (including one for fungal infection of the skin); 3 for allergy symptoms; 3 for ear or throat issues; 3 for heart-related symptoms; and 1 for nausea and vertigo. Of these, nine transferred to a different job either temporarily or permanently because of a medical condition. Overall, more than half of interviewed employees reported eye, nose, throat, and skin irritation, and many reported these symptoms improved away from work.

When asked an open-ended question about concerns over their work environment, several reported concerns about air quality and the effectiveness of ventilation and mist collectors; these data are discussed in more detail in the next paragraphs. Additionally, five employees reported that leaks of coolant on the floor were not cleaned up promptly and were a fall hazard. Occasional ammonia-like odors were also a concern.

Employees were asked if the mist collectors and general air ventilation systems in their work areas were always on and working (Figure 12), as well as about their perceptions of the effectiveness of these environmental controls in removing air contaminants from the workspace (Figure 13). Twenty-nine (35\%) employees reported that they believe the mist collectors in their work area were always on and working during their shift. Thirty-two (37\%) employees reported that they believe the general air ventilation systems in their work area were always on and working during their shift. Seventy (93\%) believed the mist collectors in their work area were either fair or poor in removing air contaminants from the workspace. Seventy-three $(87 \%)$ believed the general air ventilation system was either poor or fair at removing air contaminants from the workspace.

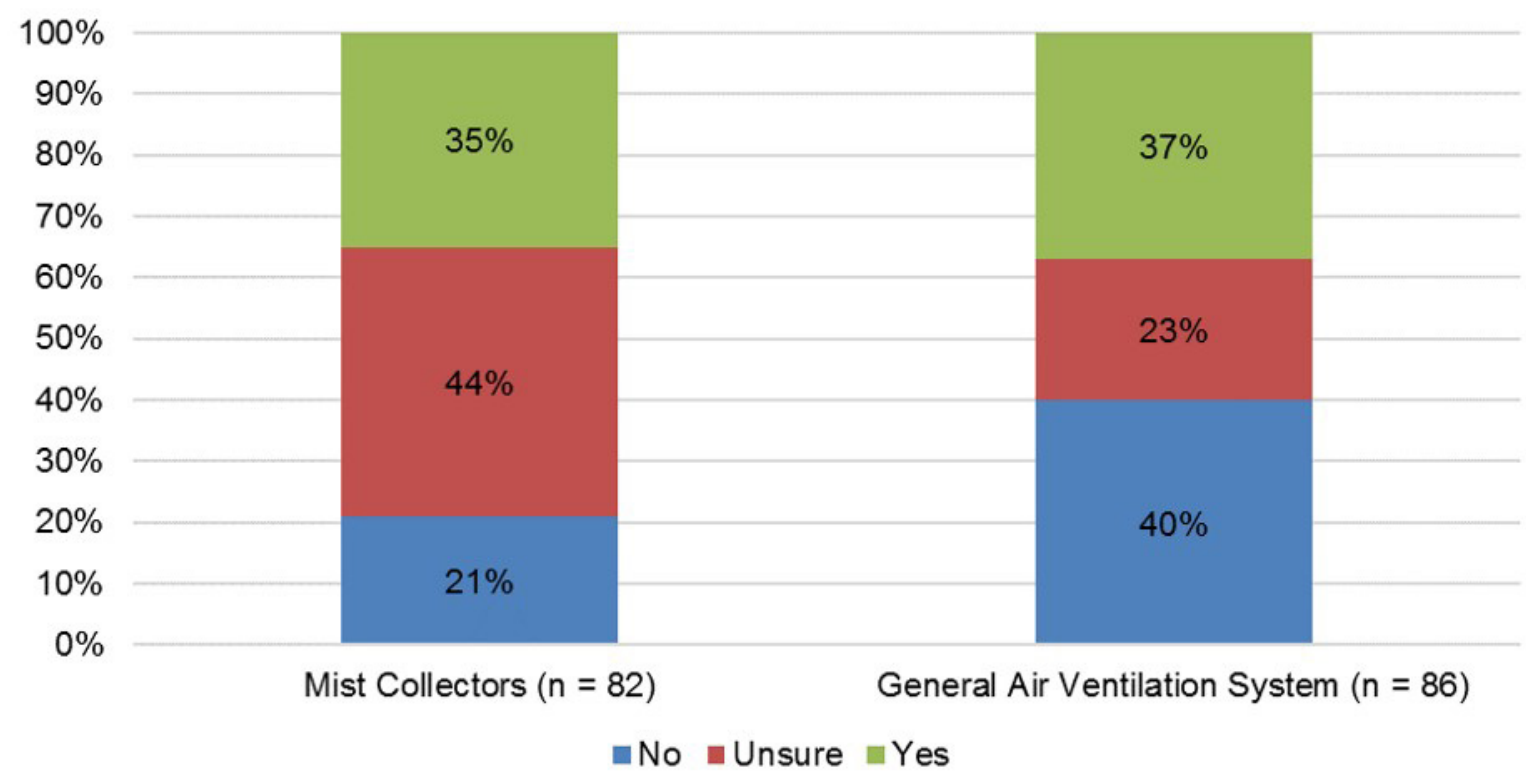

Figure 12. Employee perceptions of whether the mist collectors and general air ventilation systems in their work areas are always on and working. 


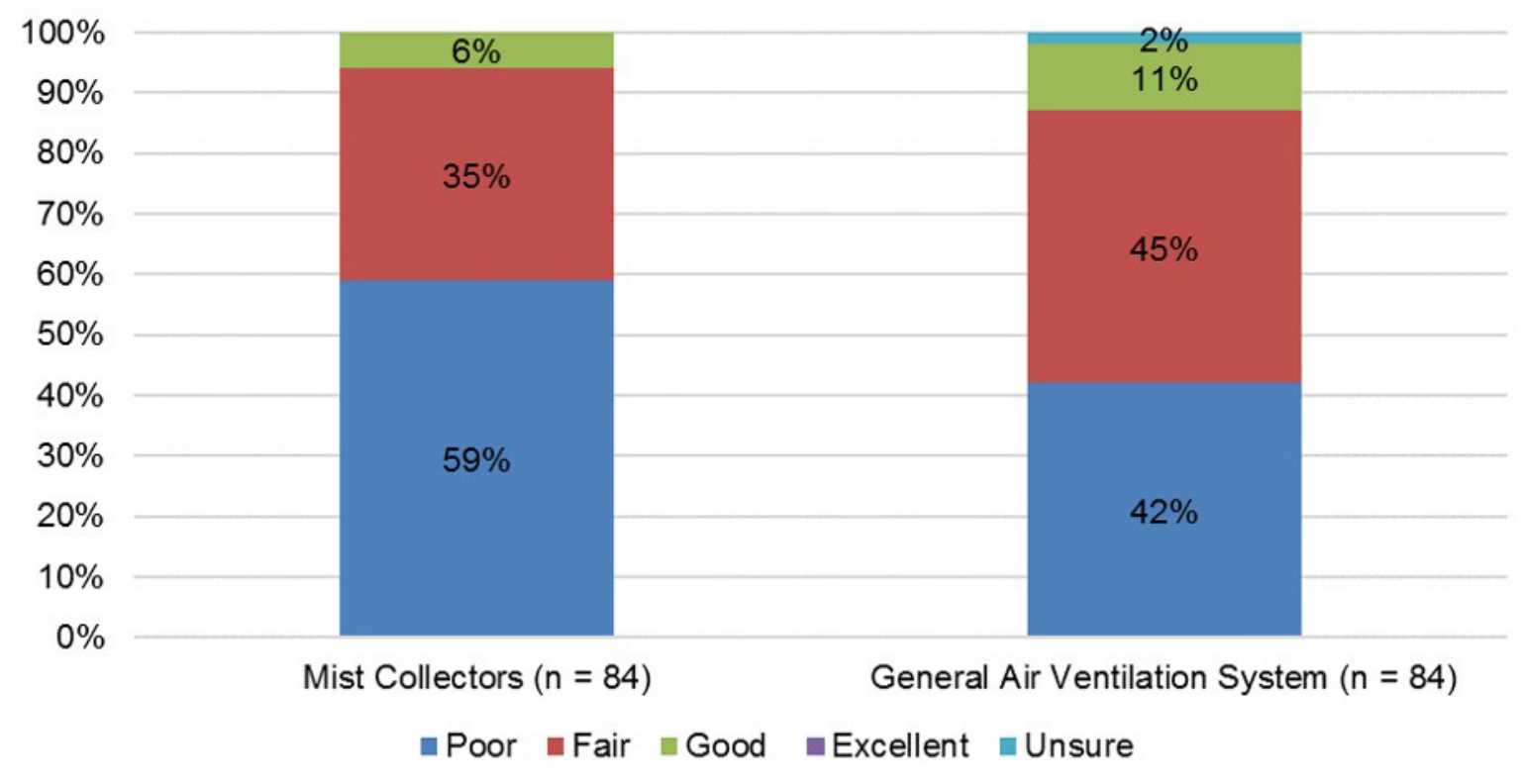

Figure 13. Employee perceptions of whether the mist collectors and general air ventilation systems in their work areas are effective in removing air contaminants from the workspace.

The average job stress score (where $0=$ no stress and $10=$ a lot of stress) among 87 respondents to this question was 3.6, indicating moderate job stress overall. Based on individual scores, 45 (52\%) employees indicated low job stress, 25 (29\%) indicated moderate job stress, and 17 (20\%) indicated high job stress.

We asked employees an open-ended question to identify what they believe contributes to their job stress. Fifty-one (57\%) employees reported one or more sources of stress. Concerns about poor air quality was the most frequently reported source of job stress $(n=13)$, followed by machines not functioning or not being maintained properly $(\mathrm{n}=11)$.

We asked all 89 employees several questions about their perceptions of how safety and health issues were addressed by the employer (Figure 14). When asked if they trust the employer to protect the well-being of employees, $56(61 \%)$ responded either "somewhat" or "yes." Sixty-eight (76\%) believed the employer is either "somewhat approachable" or "approachable" when it comes to reporting health concerns within the workforce. Fifty-four (61\%) employees reported that they are "somewhat satisfied" or "satisfied" with the communication between the employer and employees regarding health and safety issues at work. 


\section{Do you trust management in protecting the well-being of employees?}

\section{Do you believe management is approachable when it comes to reporting health concerns within the workplace?}

\section{Are you satisfied with the communication between management and employees regarding health and safety issues in the workplace?}

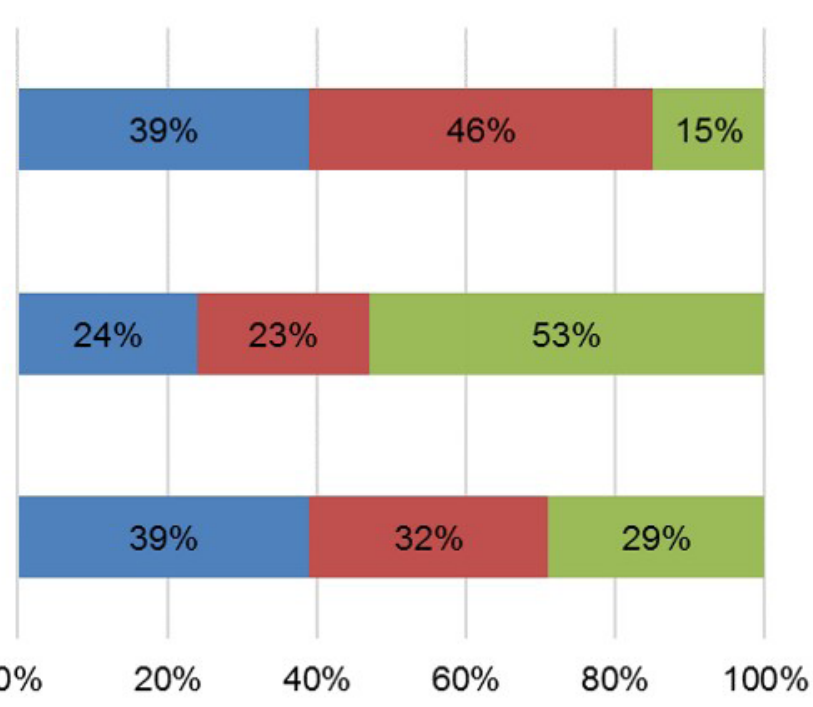

$\because$ No $\backsim$ Somewhat $\backsim$ Yes

Figure 14. Employee perceptions of the employer's trustworthiness, approachability, and communication regarding health and safety issues $(n=89)$.

Sixty-three (71\%) employees said they had reported a health or safety concern to management in the past. Of these, 24 (39\%) were either "somewhat satisfied" or "very satisfied" with how the concern was addressed by management.

All 89 employees were asked the same questions about their perceptions of how safety and health issues were addressed by the union (Figure 15). When asked if they trust the union to protect the well-being of employees, $77(87 \%)$ responded either "somewhat" or "yes." Eighty-four (94\%) believe the union is either "somewhat approachable" or "approachable" when it comes to reporting health concerns within the workforce. Seventy-six $(86 \% ; n=88)$ of employees reported that they are either "somewhat satisfied" or "satisfied" with the communication between the union and employees regarding health and safety issues at work. 
Do you trust the union in protecting the wellbeing of employees?

Do you believe the union is approachable when it comes to reporting health concerns within the workplace?

Are you satisfied with the communication between the union and employees regarding health and safety issues in the workplace?

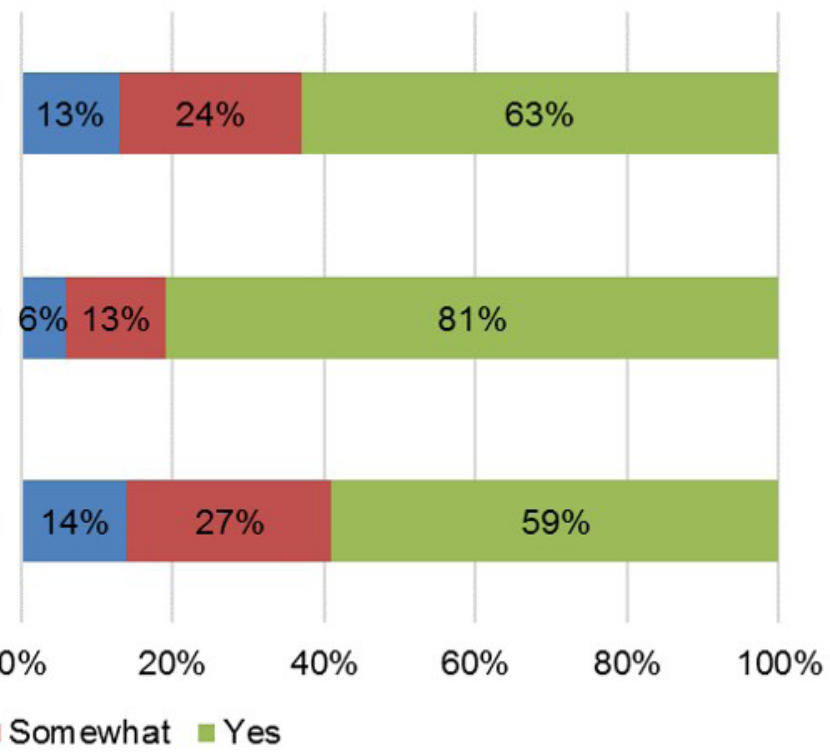

Figure 15. Employee perceptions of the union's trustworthiness, approachability, and communication regarding health and safety issues $(n=89)$.

Sixty-five (73\%) employees said they had reported a health or safety concern to the union in the past. Of these, 48 (74\%) were either "somewhat satisfied" or "very satisfied" with how the concern was addressed by the union.

\section{Employee Questionnaires}

Of 248 employees at work in the cylinder head, crankshaft, and long block assembly departments during our February 2016 visit, 172 (69\%) participated in the questionnaire, including 58 female employees. The average age of participants was 41 years (range: $21-67$ ), and the average number of years worked at the plant since hired was 10 years (range: 8 months-31 years). Of the 172 participants, 49 reported working in the cylinder head line, 33 in the crankshaft line, 84 in long block assembly, and 6 in other job areas. The average time in the job they spent the most time in over the prior month was 3 years (range: 1 month-23 years).

We asked several questions about employees' medical history. Of the 172 participating employees, 65\% reported they had a history of either childhood (atopic) eczema, asthma, or allergies. These conditions are thought to increase the risk of developing allergic respiratory and skin conditions when exposed to sensitizing compounds (allergens). Of the 61 participants $(35 \%)$ who reported ever seeing a doctor for a lung condition, 23 reported being diagnosed with lung disease after being hired by the company; 14 of the 23 believed the lung disease was related to work. Of the $40(23 \%)$ participants who reported ever seeing a doctor for a skin condition, 19 reported being diagnosed with skin disease after being hired by the company; 9 of the 19 believed the skin disease was related to work. Of the 172 participants, $45(26 \%)$ reported currently smoking cigarettes, $31(18 \%)$ reported they were former smokers, and $96(56 \%)$ reported never smoking. When we looked at these responses by work area, we found very similar percentages among all three work groups. We asked about smoking 
history because individuals who smoke typically report more respiratory symptoms than those who do not smoke.

We asked participating employees about PPE use and work hygiene practices during the month prior to our visit. Table 9 shows the results categorized by work area. Nearly all (95\%) reported wearing the required gloves every day. Among the three work areas, employees in the cylinder head department reported the highest rates of wearing aprons, protective sleeves, and respirators most days or every day. Thirteen participants reported using solvents to clean their hands at work on most days or every day in the previous month. Most participants (67\%) reported no regular exposure to chemicals outside of work in the month prior to our last site visit. Most commonly, participants reported working with the following chemicals outside of work: glues, adhesives, and tape (15\%); hydraulic or engine oils and lubricants $(12 \%)$; industrial strength cleaning agents (11\%); and solvents $(9 \%)$.

Table 9. Participating employees' reported PPE use and work hygiene in the prior month, by work area

\begin{tabular}{|c|c|c|c|}
\hline $\begin{array}{l}\text { Activities in the month prior } \\
\text { to survey }\end{array}$ & $\begin{array}{l}\text { Cylinder head } \\
(n=49) \\
\text { No. }(\%)\end{array}$ & $\begin{array}{l}\text { Crankshaft } \\
(n=33) \\
\text { No. }(\%)\end{array}$ & $\begin{array}{c}\text { Long block assembly } \\
(\mathrm{n}=83-84) \\
\text { No. }(\%)\end{array}$ \\
\hline $\begin{array}{l}\text { Coolant contacted skin at least } \\
\text { once a week }\end{array}$ & $40(82)$ & $25(76)$ & $8(10)$ \\
\hline $\begin{array}{l}\text { Used solvents at least once a } \\
\text { week to clean hands at work }\end{array}$ & $2(4)$ & $5(15)$ & $7(8)$ \\
\hline $\begin{array}{l}\text { Applied moisturizing lotion to } \\
\text { hands at least once a week } \\
\text { at work }\end{array}$ & $33(67)$ & $21(64)$ & $52(62)$ \\
\hline $\begin{array}{l}\text { Applied barrier cream at least } \\
\text { once a week at work }\end{array}$ & $14(29)$ & $5(15)$ & $6(7)$ \\
\hline $\begin{array}{l}\text { Number of times per shift } \\
\text { employee washed hands with } \\
\text { soap and water }\end{array}$ & $\begin{array}{l}\text { Median: } 7 \text { times } \\
\text { Range: } 2-50\end{array}$ & $\begin{array}{l}\text { Median: } 10 \text { times } \\
\text { Range: } 4-50\end{array}$ & $\begin{array}{l}\text { Median: } 5 \text { times } \\
\text { Range: } 2.5-12.5\end{array}$ \\
\hline $\begin{array}{l}\text { Wore gloves most days or } \\
\text { every day }\end{array}$ & $47(96)$ & $32(97)$ & $84(100)$ \\
\hline $\begin{array}{l}\text { Wore protective apron most days } \\
\text { or every day }\end{array}$ & $8(16)$ & $3(9)$ & $1(1)$ \\
\hline $\begin{array}{l}\text { Wore protective sleeves most } \\
\text { days or every day }\end{array}$ & $9(18)$ & $2(6)$ & $5(6)$ \\
\hline $\begin{array}{l}\text { Wore a respirator most days or } \\
\text { every day }\end{array}$ & $3(6)$ & 0 & $1(1)$ \\
\hline
\end{tabular}

Note: some questions had missing data because not all questions were answered by all participants 
Among the 171 participants who completed the question about skin exposure to coolant, 66 reported never having skin contact with coolant, 34 reported skin contact with coolant every day, 30 reported skin contact most days, 30 reported rarely, and 11 reported about once a week. Skin contact with coolant included coolant that soaked through gloves or clothing. Much higher percentages of cylinder head (82\%) and crankshaft (76\%) participants reported at least weekly skin exposure to coolant compared to long block assembly $(10 \%)$ participants. Interestingly, 14 participants reported cleaning their hands with solvents at least once a week, which can lead to irritant dermatitis.

We asked participants if they had dermatitis in the month prior to our visit. Of the 172 participants, 74 (43\%) reported dermatitis during this period. Of the 74 participants reporting dermatitis, $44(59 \%)$ reported that the dermatitis improved when away from work 4 or more days; $20(27 \%)$ reported the dermatitis was the same or worse, and 10 (14\%) reported they were not away from work 4 or more days in the prior month. The most common locations for dermatitis were wrists and forearms (27\%), faces and necks $(24.3 \%)$, and hands and fingers (24.1\%). Crankshaft participants reported significantly more dermatitis of the legs or ankles than long block assembly participants $(27 \%$ vs. $7 \%, P<0.01)$. However, there were no other statistically significant differences in dermatitis between job groups. Of those reporting dermatitis in the previous month, 30 (41\%) reported current dermatitis at the time of our visit, and $40 \%$ reported that they began wearing gloves in the past month because of dermatitis. One participant reported changing jobs because of dermatitis (assembly employee), but no participants took time off of work because of dermatitis. Eleven participants with dermatitis saw a medical provider for the rash in the previous month; four reported that the doctor said it was work-related (three cylinder head and one crankshaft employee).

We asked participants if they had experienced any of several respiratory symptoms and conditions in the month prior to our visit, if the symptom(s) had improved on days off work or on vacation, and then compared the responses between work areas (Table 10). We found no significant differences in reporting work-related nasal and respiratory symptoms between cylinder head, crankshaft, and assembly participants. Work-related nasal symptoms were the most commonly reported symptom among all participants (45\%-55\%). Asthmalike symptoms were also commonly reported (40\%-55\%), and work-related asthma-like symptoms were reported in about $30 \%$ of each job group. 
Table 10. Participants' reports of work-related* nasal and respiratory symptoms in the month prior to the questionnaire, by work area

\begin{tabular}{|c|c|c|c|c|}
\hline Symptom & $\begin{array}{c}\text { Cylinder head } \\
(\mathrm{n}=48-49) \\
\text { No. }(\%)\end{array}$ & $\begin{array}{c}\text { Crankshaft } \\
(n=32-33) \\
\text { No. }(\%)\end{array}$ & $\begin{array}{c}\text { Long block } \\
\text { assembly } \\
(\mathrm{n}=82-84) \\
\text { No. }(\%)\end{array}$ & $\begin{array}{c}\text { Statistica } \\
\text { test } \\
P \text { value }\end{array}$ \\
\hline Work-related nasal symptoms & $23(47)$ & $18(55)$ & $37(45)$ & 0.62 \\
\hline Work-related wheeze & $12(25)$ & $9(27)$ & $22(27)$ & 0.97 \\
\hline Work-related chest tightness & $7(14)$ & $6(18)$ & $12(14)$ & 0.86 \\
\hline $\begin{array}{l}\text { Asthma attack less frequent away } \\
\text { from work }\end{array}$ & $2(4)$ & $1(3)$ & $3(4)$ & 1.00 \\
\hline $\begin{array}{l}\text { Use of asthma medication less } \\
\text { away from work }\end{array}$ & $5(10)$ & $3(9)$ & $6(7)$ & 0.76 \\
\hline $\begin{array}{l}\text { Work-related asthma-like } \\
\text { symptoms } \dagger\end{array}$ & $15(31)$ & $10(30)$ & $24(29)$ & 0.97 \\
\hline
\end{tabular}

Note: some questions had missing data because not all questions were answered by all participants.

*Defined as symptoms that improved away from work on days off or on vacation.

†Work-related asthma-like symptoms were defined as having one or more of the following: less use of asthma medicine when away from work, wheezing or whistling in the chest in the past month that improves away from work, awakening with a feeling of chest tightness in the past month that improves away from work, or attacks of asthma in the past month that are less frequent away from work.

Table 11 below shows the number of participants reporting the use of compressed air, coolant spray, or water spray to clean machines or machined parts in the month prior to our visit.

Some reported using more than one method. Long block assembly participants generally did not clean parts with coolant or water spray and few used compressed air to clean parts.

Table 11. Participating employees' reported use of compressed air, coolant spray, or water spray to clean machines or machined parts in the month prior to our visit, by work area

\begin{tabular}{lccc}
\hline $\begin{array}{l}\text { Responses about cleaning } \\
\text { activities in the month prior } \\
\text { to survey }\end{array}$ & $\begin{array}{c}\text { Cylinder head } \\
(\mathrm{n}=47-49) \\
\text { No. }(\%)\end{array}$ & $\begin{array}{c}\text { Crankshaft } \\
(\mathrm{n}=31-32) \\
\text { No. }(\%)\end{array}$ & $\begin{array}{r}\text { Long block assembly } \\
(\mathrm{n}=79-82) \\
\text { No. }(\%)\end{array}$ \\
\hline $\begin{array}{l}\text { Frequently used compressed air } \\
\text { to clean parts or machines }\end{array}$ & $26(54)$ & $16(52)$ & $8(10)$ \\
$\begin{array}{l}\text { Frequently used coolant spray to } \\
\text { clean parts or machines }\end{array}$ & $27(57)$ & $15(47)$ & 0 \\
$\begin{array}{l}\text { Frequently used water spray to } \\
\text { clean parts or machines }\end{array}$ & $21(43)$ & $3(10)$ & $2(2)$ \\
\hline
\end{tabular}

We also grouped participants by the type of cleaning method used (compressed air, coolant spray, or water spray) and looked at their reported respiratory and dermal symptoms (Table 12). Participants who cleaned with coolant spray frequently, as compared to those who never or sometimes cleaned with coolant spray, reported twice the prevalence of work-related wheezing (Prevalence Ratio $(\mathrm{PR})=1.99, \mathrm{CI}=1.17-3.39)$ and work-related asthma-like symptoms $(\mathrm{PR}=2.07, \mathrm{CI}=1.29-3.33)$. Those participants who cleaned with water spray frequently, as compared to those who never or sometimes cleaned with water spray, reported 
a significantly higher prevalence of work-related asthma-like symptoms $(\mathrm{PR}=1.83$, $\mathrm{CI}=1.11-3.04)$. Participants who cleaned with compressed air frequently, as compared to those who never or sometimes cleaned with compressed air, reported a significantly higher prevalence of work-related nasal symptoms in the month prior to the survey $(\mathrm{PR}=1.80$, $\mathrm{CI}=1.33-2.44)$. This group of participants also reported nearly three times the prevalence of dermatitis on the day of the survey $(\mathrm{PR}=2.81, \mathrm{CI}=1.46-5.39)$.

Table 12. Prevalence ratio* of reported work-related symptoms among participants using a cleaning method that occurred in the month prior to questionnaire, by type of cleaning method

\begin{tabular}{|c|c|c|c|}
\hline Work-related symptom $\dagger$ & $\begin{array}{l}\text { Cleaned frequently } \\
\text { with water spray } \\
\text { compared to } \\
\text { sometimes or never } \\
(n=24-26) \\
\text { PR }(\mathrm{Cl}) \ddagger\end{array}$ & $\begin{array}{l}\text { Cleaned frequently } \\
\text { with coolant spray } \\
\text { compared to } \\
\text { sometimes or never } \\
(n=39-42) \\
\text { PR }(\mathrm{Cl})\end{array}$ & $\begin{array}{l}\text { Cleaned frequently with } \\
\text { compressed air } \\
\text { compared to } \\
\text { sometimes or never } \\
(n=47-50) \\
\text { PR }(\mathrm{Cl})\end{array}$ \\
\hline $\begin{array}{l}\text { Wheezing that was better } \\
\text { away from work }\end{array}$ & $1.74(0.98-3.09)$ & $1.99(1.17-3.39) \S$ & $1.47(0.84-2.58)$ \\
\hline $\begin{array}{l}\text { Tightness in chest was } \\
\text { better away from work }\end{array}$ & $1.60(0.36-3.81)$ & $1.77(0.79-3.98)$ & $1.40(0.62-3.17)$ \\
\hline $\begin{array}{l}\text { Attacks of asthma less } \\
\text { frequent away from work }\end{array}$ & $1.13(0.04-7.73)$ & $1.48(0.20-8.10)$ & $1.16(0.16-6.41)$ \\
\hline $\begin{array}{l}\text { Breathing medicine taken } \\
\text { less often when away } \\
\text { from work }\end{array}$ & $1.37(0.18-4.26)$ & $1.45(0.36-3.96)$ & $1.15(0.28-3.17)$ \\
\hline $\begin{array}{l}\text { Sneezing, runny nose, or } \\
\text { blocked nose (not } \\
\text { associated with a cold or } \\
\text { flu) less frequent when } \\
\text { away from work }\end{array}$ & $1.40(0.98-2.00)$ & $1.30(0.94-1.82)$ & $1.80(1.33-2.44)$ \\
\hline $\begin{array}{l}\text { Work-related asthma-like } \\
\text { symptoms } \mathbb{}\end{array}$ & $1.83(1.11-3.04)$ & $2.07(1.29-3.33)$ & $1.49(0.91-2.45)$ \\
\hline $\begin{array}{l}\text { Dermatitis that improved } \\
\text { when away from work } \\
\geq 4 \text { days }\end{array}$ & $1.48(0.82-2.67)$ & $0.61(0.29-1.26)$ & $1.19(0.69-2.06)$ \\
\hline
\end{tabular}

*The prevalence ratio compares the prevalence of the symptom among those who frequently cleaned with one method with the prevalence of the symptom among those who sometimes or never cleaned with that method.

†Work-related symptoms were defined as symptoms that improved away from work on days off or on vacation.

$\$ 95 \%$ confidence interval

§Bold font indicates PR values are statistically significant.

TWork-related asthma-like symptoms were defined as having one or more of the following: less use of asthma medicine when away from work, wheezing or whistling in the chest in the past month that improves away from work, awakening with a feeling of chest tightness in the past month that improves away from work, or attacks of asthma in the past month that are less frequent away from work. 
We asked participants if the symptoms they thought were work-related in the previous 12 months had improved in the past month. Among the 172 participating employees, 25 (15\%) reported not having symptoms in the previous 12 months, and three did not respond to the question. Of the 144 participants who reported work-related symptoms in the 12 months prior to the questionnaire, most (62\%) reported no improvement of those symptoms in the month prior to the questionnaire; $38 \%$ reported improvement or some improvement of symptoms.

When asked to rate the air quality in their primary work area over the last 30 days, most participants described it as "fair" (48\%) or "poor" (33\%). Thirty-three (19\%) participants described the air as "good," yet no participants rated it as "excellent." Table 13 shows these results by work area.

Table 13. Participant perceptions of air quality in the past month by work area

\begin{tabular}{lccccc}
\hline $\begin{array}{l}\text { Participant } \\
\text { perception }\end{array}$ & $\begin{array}{c}\text { Cylinder head } \\
(\mathrm{n}=49)\end{array}$ & $\begin{array}{c}\text { Crankshaft } \\
(\mathrm{n}=33)\end{array}$ & $\begin{array}{c}\text { Long block } \\
\text { assembly } \\
(\mathrm{n}=84)\end{array}$ & $\begin{array}{c}\text { Other area } \\
(\mathrm{n}=6)\end{array}$ & $\begin{array}{c}\text { Total } \\
(\mathrm{n}=172)\end{array}$ \\
\hline Poor & $20(41)$ & $11(33)$ & $25(30)$ & $1(17)$ & $57(33)$ \\
Fair & $23(47)$ & $17(52)$ & $40(48)$ & $2(33)$ & $82(48)$ \\
Good & $6(12)$ & $5(15)$ & $19(23)$ & $3(50)$ & $33(19)$ \\
Excellent & $0(0)$ & $0(0)$ & $0(0)$ & $0(0)$ & $0(0)$ \\
\hline
\end{tabular}

When asked to rate the communication between the employer and employees regarding recent efforts to improve employee safety and health (for example, changes to the work environment or the way the work is performed), most participants described it as "poor" (40\%) or "fair" (39\%). Twenty-eight (16\%) participants described communication as "good," and $8(5 \%)$ described it as "excellent." Table 14 shows these results by work area.

Table 14. Participant perceptions of the employer's health and safety communication in the past month by work area

\begin{tabular}{lccccc}
\hline $\begin{array}{l}\text { Participant } \\
\text { perception }\end{array}$ & $\begin{array}{c}\text { Cylinder head } \\
(\mathrm{n}=49)\end{array}$ & $\begin{array}{c}\text { Crankshaft } \\
(\mathrm{n}=33)\end{array}$ & $\begin{array}{c}\text { Long block } \\
\text { assembly } \\
(\mathrm{n}=84)\end{array}$ & $\begin{array}{c}\text { Other area } \\
(\mathrm{n}=6)\end{array}$ & $\begin{array}{c}\text { Total } \\
(\mathrm{n}=172)\end{array}$ \\
\hline Poor & $16(33)$ & $15(45)$ & $36(43)$ & $2(33)$ & $69(40)$ \\
Fair & $18(37)$ & $12(36)$ & $37(44)$ & $0(0)$ & $67(39)$ \\
Good & $11(22)$ & $6(18)$ & $9(11)$ & $2(33)$ & $28(16)$ \\
Excellent & $4(8)$ & $0(0)$ & $2(2)$ & $2(33)$ & $8(5)$ \\
\hline
\end{tabular}


When asked whether they believe their employer is committed to protecting the safety and health of its employees, 85 (50\%) participants responded "somewhat," 45 (26\%) responded "yes," and 41 (24\%) responded "no." Table 15 shows these results by work area.

Table 15. Participant responses to "Do you think your employer is committed to protecting the safety and health of its employees?" by work area

\begin{tabular}{lccccc}
\hline $\begin{array}{l}\text { Participant } \\
\text { response }\end{array}$ & $\begin{array}{c}\text { Cylinder head } \\
(\mathrm{n}=49)\end{array}$ & $\begin{array}{c}\text { Crankshaft } \\
(\mathrm{n}=33)\end{array}$ & $\begin{array}{c}\text { Long block } \\
\text { assembly } \\
(\mathrm{n}=83)\end{array}$ & $\begin{array}{c}\text { Other area } \\
(\mathrm{n}=6)\end{array}$ & $\begin{array}{c}\text { Total } \\
(\mathrm{n}=171)\end{array}$ \\
\hline No & $11(22)$ & $11(33)$ & $18(22)$ & $1(17)$ & $41(24)$ \\
Somewhat & $26(53)$ & $12(36)$ & $45(54)$ & $2(33)$ & $85(50)$ \\
Yes & $12(24)$ & $10(30)$ & $20(24)$ & $3(50)$ & $45(26)$ \\
\hline
\end{tabular}

\section{Discussion}

Our evaluation found a high prevalence of respiratory symptoms despite MWF levels below the NIOSH REL. This is consistent with NIOSH findings that employees can develop respiratory symptoms at MWF levels below OELs [NIOSH 1998a] and has been confirmed by studies in the scientific literature [Lillienberg et al. 2010; Park et al. 2008]. One study found significantly more upper and lower respiratory symptoms among employees exposed to a mean value of total MWF aerosols of $0.4 \mathrm{mg} / \mathrm{m}^{3}$, which is below the NIOSH REL for total MWF aerosols of $0.5 \mathrm{mg} / \mathrm{m}^{3}$, compared to unexposed employees [Lillienberg et al. 2010]. Park et al. [2008] studied an auto parts manufacturing employee population; $61 \%$ of MWF-exposed employees reported rhinitis-related symptoms. Air sampling collected by Park et al. [2008] found that $82 \%$ of employees were exposed to total MWF levels at or below $0.5 \mathrm{mg} / \mathrm{m}^{3}$. Looking at the general population, Guerra et al. [2002] found rhinitis (defined as runny or stuffy nose or episodes of sneezing apart from a cold) to be a significant risk factor for adult-onset asthma in those with and without history of allergies.

We found that cylinder head and crankshaft employees had skin exposure to MWF. We observed employees in all departments did not consistently adhere to the required PPE use. For example, employees wore shorts and sleeveless shirts instead of long pants and long sleeved shirts, and also did not consistently wear the required chemically-resistant gloves when handling MWF. We also saw cylinder head and crankshaft employees using compressed air or spraying coolant or water to dislodge built-up metal chips inside equipment. Such a practice can increase airborne levels of MWF mist as well as increase the potential for dermal exposure. We observed MWF on some employees' skin while they were working.

During our first site visit, through interviews, skin examination, and medical record review, we found several cylinder head employees with skin and respiratory symptoms that appeared to be work-related. Many of these employees believed that their MWF exposure in the cylinder head department was greater than the MWF exposure in other departments. During the second site visit, we measured and compared the MWF exposures and work-related symptom prevalence for the crankshaft machining line, the cylinder head machining line, and 
the long block assembly line. Although we did not identify a significant difference between employees' airborne MWF exposures in the cylinder head line and crankshaft machining line, both of these departments did exhibit significantly higher MWF exposures when compared to the long block assembly line.

Our screening questionnaire responses indicate that over $40 \%$ of all participating employees reported work-related nasal symptoms, and about 30\% reported work-related asthmalike symptoms. When comparing participants by job area, the prevalence of work-related respiratory, nasal, and skin symptoms reported by cylinder head, crankshaft, and long block assembly line participants did not differ significantly. However, significant nasal and respiratory findings were revealed when we grouped participants by their frequency of using compressed air, water spray, or MWF spray to clean machines and machined parts. Participants reporting frequent use of coolant spray, water spray, or compressed air had a higher prevalence of some work-related symptoms compared to those who sometimes or never used coolant spray, water spray, or compressed air. Our questionnaire results showed that over $53 \%$ of cylinder head participants used coolant spray and compressed air, and over $40 \%$ used water spray to clean parts or the machine. Over $45 \%$ of crankshaft participants used compressed air and coolant spray; only 10\% used water spray. Long block assembly participants rarely used these cleaning methods. We did not evaluate why assembly participants reported nearly the same prevalence of respiratory symptoms as the crank line and cylinder head line participants, but it is possible that different exposures, such as rose water or oil used in assembly tasks, may be responsible.

Video exposure monitoring in a recent health hazard evaluation has shown that using compressed air to blow off parts and machines caused short-term peak MWF mist exposures, which indicates that MWF is aerosolized during such an activity [NIOSH 2016]. Using MWF spray or water spray to clean parts and machines could also cause aerosolization of MWF. Our findings that associate the respiratory symptoms with these cleaning tasks suggest that such a route of exposure is plausible.

After analyzing questionnaire responses from the second visit, we found that over $40 \%$ of all participants reported dermatitis on at least one body location in the month prior to the questionnaire, which is higher than recent studies by Berndt et al. (23\%) and Apfelbacher et al. (30\%) [Apfelbacher et al. 2008; Berndt et al. 2000]. Over 75\% of cylinder head and crankshaft participants reported coolant contacting their skin at least once a week. Some participants reported using solvents to clean their skin, which can lead to irritant dermatitis. We also found that crankshaft machining participants reported significantly more dermatitis of the legs and ankles than long block assembly participants. We could not determine the specific reason for the increased dermatitis of the legs and ankles in these employees, although we did observe some employees wearing shorts. Other than these dermatitis findings, there were no other significant differences in work-related skin symptoms between cylinder head, crankshaft, or long block assembly line participants. We did not analyze the impact of the use of a tool to dislodge the metal chips.

Skin contact with MWFs is known to cause allergic contact dermatitis, irritant contact dermatitis, or oil folliculitis (irritation or infection of hair follicles) depending on the 
chemical composition, additives and contaminants, type of metal being machined, and the exposed individual's tendency for developing allergies [Chew and Maibach 2003; Slodownik et al. 2008; WISHA 2001]. The use of compressed air, water spray, and coolant spray by machine operators, who often had much exposed skin on their arms and legs, presented a plausible route of skin exposure even when the machine operators used gloves. Limiting skin exposure is critical to preventing allergic and irritant skin disorders related to MWF exposure. Studies have shown that about one in four employees diagnosed with occupational contact dermatitis will have persistent symptoms despite treatment or job change [Cretkovski et al. 2006; Jungbauer et al. 2004]. Additional information about contact dermatitis and tips to reduce or prevent work-related contact dermatitis are given in Appendix D.

Limiting exposure to MWF aerosols is also prudent because previous exposures to some MWFs have been associated with increased risk of some types of cancer [NIOSH 2013]. Sullivan et al. found esophageal cancer was significantly associated with exposure to both soluble and synthetic MWF in grinding operations; the elevated risk was associated with nitrosamines $(\mathrm{OR}=5.4, \mathrm{CI}=1.5-19.9)$ and biocides $(\mathrm{OR}=3.8, \mathrm{CI}=0.8-18.9)$ [Sullivan et al. 1998]. Laryngeal cancer has been associated with exposure to straight mineral oils, but thought to be due to polyaromatic hydrocarbons or to sulfur additives [Eisen et al. 1994]; neither of these compounds pertain to the MWF used in this plant. Although actions taken in the last several decades have reduced the cancer risk from MWF exposure, it is not known if these actions have totally eliminated the risk [NIOSH 2013].

Prior to our first site visit in August 2015, a consultant that the company hired found DCHA in air samples. Employees and company managers were concerned that the DCHA was causing skin and respiratory symptoms among cylinder head employees. According to the safety data sheets, Quakeral 481 (used in the cylinder headline in August 2015) contained $1 \%-15 \%$ MEA, $1 \%-5 \%$ TEA, and 1\%-5\% other amines (including DCHA). Our bulk MWF sampling collected in August 2015 confirmed this; DCHA was present in the concentrated and the process samples. Between August 2015 and February 2016, the company changed the cylinder head line coolant from Quakeral 481 to Quakeral 490. According to the safety data sheets, Quakeral 490 (used in the cylinder headline in February 2016) and Quakercool 3511 (used in the crankline in August and February) did not contain DCHA. Our sampling indicated that the concentrated, unused MWFs did not contain DCHA. However, the process samples collected in February did. In addition, although the total number of area air samples that contained DCHA were less in February (2 of 10) than in August (10 of 17), the highest concentration in February $\left(0.58 \mathrm{mg} / \mathrm{m}^{3}\right)$ was higher than the highest concentration in August $\left(0.14 \mathrm{mg} / \mathrm{m}^{3}\right)$. We suspect that when the plant changed MWFs between August and February, they did not completely purge the MWF system of residual DCHA-containing MWF. In addition, we did not collect personal air samples for DCHA during the second visit to compare with employees' reported symptoms, and were unable to evaluate whether or not DCHA was associated with employee respiratory and skin symptoms. Since employees continued to report skin and respiratory symptoms in February 2016, DCHA was unlikely to be the major cause of these symptoms. Another finding from our bulk MWF sample (Quakeral 490) was the presence of two unknown chemicals. These two chemicals were more prevalent than any of the other analytes we were looking for. Our NIOSH chemists 
suspected that one chemical was a cyclized product of TEA and the other was a cyclized product of DEA. Cyclized products are chemicals that are created by a chemical reaction in an acidic environment. Because we could not identify these chemicals, we cannot determine their health effects, or if their presence is adding to the respiratory and dermal symptoms.

The general ventilation system introduced and exhausted air at the ceiling level, a design that may not provide good mixing at the floor level to dilute air contaminants in the employee breathing zone. The presence of fluid droplets on the mist collector exhaust and dripping from the mist collector exhaust suggests that filter bypass is likely occurring. The cause of filter bypass is probably because the filters do not fit correctly, have degraded over time, or have become damaged. Because the mist collectors discharged filtered air into the work environment, it is important that filters limit discharge of contaminants into the air. Although the plant did have a filter change out schedule, it might not have been sufficiently frequent. The filter change out schedule was based on time in service and a measured pressure drop across the filter using a magnehelic gauge. Appropriate filter change-out schedules or periodic filter checks can help ensure that filters work effectively.

The employee interviews and questionnaires revealed that employees were concerned about the air quality in their workplace and how it may potentially affect their health. Perceptions that the mist collectors and air vents were not always functioning properly or were poorly maintained may be linked to why most employees expressed distrust in the employer's willingness to look out for the well-being of employees. Although the plant had a preventive maintenance program to maintain the mist collectors, these maintenance procedures were not well communicated to the employees. Some employees expressed frustration that their reports of safety and health concerns related to machine maintenance and air quality were not being addressed to their satisfaction, which also may have affected their level of trust in the employer. This is evidenced by the lack of knowledge of the preventive maintenance program for the mist collectors and all other mechanical systems. It is important that the employer and the union regularly consult with employees about their health and safety concerns and explain to employees how the concerns will be addressed or why they cannot be addressed. Doing so may strengthen positive perspectives of the employer's willingness to care for the well-being of the employees and lead to improvements in safety systems [Vecchio-Sudus and Griffiths 2004].

\section{Limitations}

1. About $30 \%$ of employees did not participate in the questionnaire.

2. Our questionnaire collected self-reported symptoms and medical conditions. This could be a potential source of bias because over-reporting of symptoms and medical conditions, possibly from heightened awareness of long-standing employee concerns, can over-estimate the true prevalence of symptoms and disease. About $65 \%$ of employees reported a history of atopic conditions (eczema, asthma, and/or allergic rhinitis), indicating an allergic predisposition. Studies have found that about $20 \%$ of the general population have a history of atopic conditions [Bantz 2014]. We are unsure why the employees of this plant reported three times the prevalence of atopic conditions compared to the general population, but it may be from over-reporting, or 
misunderstanding the question. This may also contribute to the high prevalence of asthma (30\%) among participating employees.

3. We altered the time frame of Grassi's symptom questions used to characterize asthma from "in the past 12 months" to "in the past 1 month." Because of this, we do not know the specificity or sensitivity of the questions, and they may overestimate or underestimate the true prevalence of asthma.

4. We used long block assembly employees as a comparison group. While they had little exposure to MWF, they may have had exposures to other chemicals, such as rose water, that could cause dermatitis and respiratory symptoms.

5. We only collected samples over four shifts, and these results may not be generalizable to all exposures.

\section{Conclusions}

Employees reported a high prevalence of work-related nasal (45\%-55\%), respiratory (29\%-31\%) and skin (25\%) symptoms, and we found skin exposure to MWF among cylinder head and crankshaft line employees. All MWF mist levels measured during the evaluation were below OELs. However, NIOSH has evaluated research that suggests that exposure to airborne MWF levels below the current NIOSH-recommended limits can cause or exacerbate respiratory symptoms. We observed employees not wearing the required protective clothing and using work practices that could increase the risk for skin exposure to MWF. We found that work-related nasal and respiratory symptoms reported by employees were significantly associated with the three methods used to clean machines and machine parts: compressed air, water spray, and coolant spray. Poor air quality was a prominent concern among employees. Most employees reported that they did not trust management to look out for their well-being, and that management handled employee concerns poorly. We provide specific recommendations to assist management in reducing the risk of employee dermal and respiratory problems related to MWF exposures in the plant.

\section{Recommendations}

On the basis of our findings, we recommend the actions listed below. We encourage the engine machining plant to use a labor-management health and safety committee or working group to discuss our recommendations and develop an action plan. Those involved in the work can best set priorities and assess the feasibility of our recommendations for the specific situation at the engine machining plant.

Our recommendations are based on an approach known as the hierarchy of controls (Appendix C). This approach groups actions by their likely effectiveness in reducing or removing hazards. In most cases, the preferred approach is to eliminate hazardous materials or processes and install engineering controls to reduce exposure or shield employees. Until such controls are in place, or if they are not effective or feasible, administrative measures and PPE may be needed. 


\section{Engineering Controls}

Engineering controls reduce employees' exposures by removing the hazard from the process or by placing a barrier between the hazard and the employee. Engineering controls protect employees effectively without placing primary responsibility of implementation on the employee.

1. Consult the mist collector manufacturer for guidance on eliminating exhaust air bypassing the filters. Make sure filter change out schedules are adequate.

2. Extend the mist collector ductwork and exhaust air to the roof or improve the supply airflow throughout the floor levels of the cylinder head line by further extending the ductwork of the heating, ventilation, and air-conditioning system or by redesigning the system so that supply air is introduced at the floor level.

3. Eliminate the use of compressed air, coolant spray, and/or water spray to dislodge chips inside the machines and/or clean parts. Consult with mechanical engineers to design machines that do not need chips to be dislodged manually. Until compressed air, coolant spray, and water spray is eliminated, use longer spray wands that extend inside the machines, a short pole with a hook on the end, add splash guards to the wands, and reduce air pressure for dislodging and removing metal chips.

\section{Administrative Controls}

The term administrative controls refers to employer-dictated work practices and policies to reduce or prevent hazardous exposures. Their effectiveness depends on employer commitment and employee acceptance. Regular monitoring and reinforcement are necessary to ensure that policies and procedures are followed consistently.

1. Maintain a comprehensive preventive MWF maintenance program, as specified in Chapter 9 of the NIOSH document, "Criteria for a Recommended Standard: Occupational Exposure to Metalworking Fluids" [NIOSH 1998a]. This includes cleaning and maintaining mist collectors regularly. More information about the function and maintenance of MWF mist collectors can be found in OSHA's

"Metalworking Fluids: Safety and Health Best Practices Manual" at https://www.osha.gov/SLTC/metalworkingfluids/metalworkingfluids manual.html [OSHA 2000].

2. Implement an exposure monitoring program for MWF in air. All employees exposed to MWF should be included in the air monitoring program. Perform personal exposure monitoring when process or production level changes have been made. Notify workers of all sampling results.

3. Train all employees who will be handling MWF on the proper handling and use of MWF and on the hazards and potential health effects associated with MWF exposure upon entering the workforce and annually thereafter. Include information on how to avoid skin irritation, such as by washing their arms up to the elbows whenever they wash their hands at work. Also include information on how to carefully select moisturizers, soaps, and skin cleaners because some components such as lanolin and fragrances are known allergens and may cause allergic contact dermatitis in sensitive 
individuals. Guidelines for MWF training are included in the NIOSH document "What You Need to Know about Occupational Exposure to Metalworking Fluids" at https://www.cdc.gov/niosh/docs/98-116/pdfs/98-116.pdf [NIOSH 1998b].

4. Evaluate all new processes, process changes, or product changes regarding their impact on employee exposures and possible effects on employee respiratory and dermal health. As part of managing health risks of product changes, consult with the product manufacturers about reported health risks, perform exposure monitoring to carefully monitor the impact of the change of product on exposures, and closely monitor changes in employee reported health effects.

5. Clean up MWF spills promptly, and determine the root cause for the leak.

6. Stop using solvents to clean skin. Provide employees with nonirritating cleaning agents and soaps at wash stations.

7. Consider periodic use of a medical questionnaire that focuses on skin and respiratory symptoms as part of the medical monitoring program for employees exposed to MWFs. The questionnaire should be given before placement in a job with MWF exposure and periodically thereafter. Questionnaire responses can help identify work areas and tasks that need additional evaluation and employees who need additional medical follow-up. A medical monitoring program helps prevent, identify, and manage skin and respiratory disease among included employees. More information about medical monitoring and its implementation can be found in the NIOSH document "What You Need to Know about Occupational Exposure to Metalworking Fluids" at https://www.cdc.gov/niosh/docs/98-116/pdfs/98-116.pdf [NIOSH 1998b].

8. Encourage employees to report all potential work-related skin or respiratory problems to their supervisors. Employees with persistent symptoms should be evaluated by an occupational medicine physician or a medical provider specializing in workplace illnesses. The Association of Occupational and Environmental Clinics has an online directory of such providers at http://www.aoec.org/directory.htm. Employees with definite or possible occupational skin or respiratory diseases should be protected from exposures to substances that cause or exacerbate the disease. In some cases of allergic contact dermatitis and allergic occupational asthma, employees may have to be reassigned with retention of pay and employment status to areas where exposure is minimal or nonexistent.

9. Monitor injury and illness logs routinely to identify particular job duties, work materials, machines, or areas of the plant that may be associated with high numbers of workplace injuries and illnesses. Focus on these areas for preventive actions.

10. Encourage employees to discuss their work exposures with their primary healthcare provider and to share any exposure sampling records and any health concerns with him or her. 
11. Improve communication between the employer and employees regarding responses to employee health and safety concerns. Improving communication may lead to more favorable employee perceptions of the employer's trustworthiness and approachability when it comes to health and safety concerns. A supervisor or manager who is sensitive to the employees' concerns should communicate directly with those who report health and safety concerns. Points to consider include the following:

a. Actively listening to employees' concerns in a nonjudgmental manner. Employees should feel that their concerns are taken seriously.

b. Regularly informing employees of exactly what steps are being taken to assess the problem, what has been determined, and what remains to be determined. A combination of written reports and face-to-face meetings is valuable.

c. Routinely sharing information with employees rather than waiting until a definitive cause of the problem is discovered; this will reduce the chance of distorted information.

12. Implement a smoking cessation program for employees who smoke.

\section{Personal Protective Equipment}

PPE is the least effective means for controlling hazardous exposures. Proper use of PPE requires a comprehensive program and a high level of employee involvement and commitment. The right PPE must be chosen for each hazard. Supporting programs such as training, change-out schedules, and medical assessment may be needed. PPE should not be the sole method for controlling hazardous exposures. Rather, PPE should be used until effective engineering and administrative controls are in place.

1. Enforce consistent PPE use in areas where dermal exposure to MWFs can occur. Remind employees that they must wear long pants and shirts with long sleeves and are required to wear chemical resistant gloves whenever machine operators could possibly come in contact with MWF.

2. Enforce respirator, sleeve, and glove use during manual dislodging of machine chips until compressed air, coolant spray, and water spray is eliminated.

3. Train employees and supervisors on how to insert hearing protectors properly and on the importance of proper hearing protector fit. Remind employees that electronic ear buds are not hearing protection. 


\section{Appendix A: Figure}

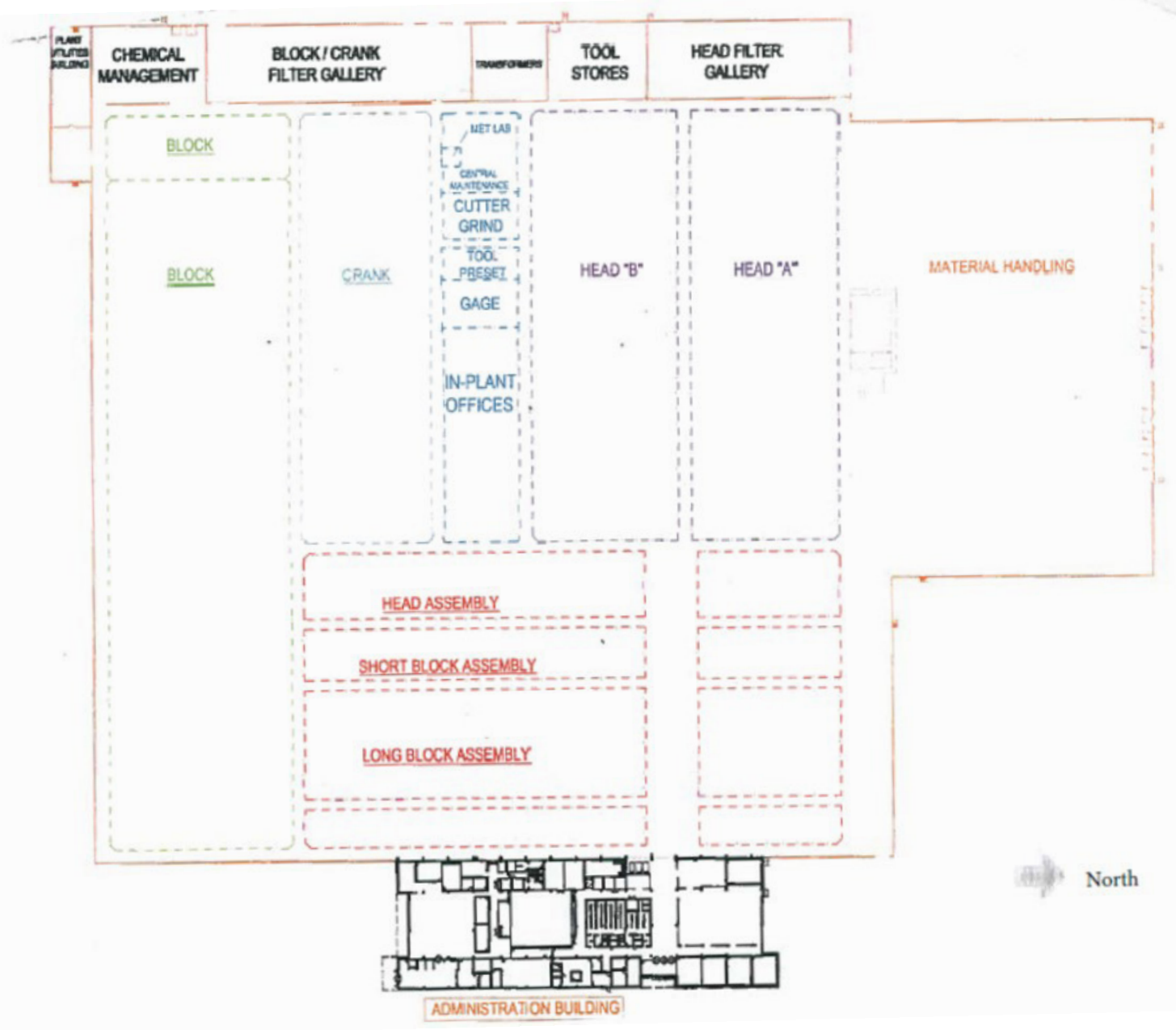

Figure A1. Floor plan of the south plant. Figure provided by the company. 


\section{Appendix B: Methods}

\section{Medical Interviews and Questionnaires}

In August 2015, we used a semi-structured interview form to complete confidential medical interviews. In addition to asking employees about exposures, medical history, and symptoms related to work, we asked employees to rate their level of job stress with the following question: "During the past week, including today, how would you rate your current job stress level on a scale from 0 (as low as it can be) to 10 (as high as it can be)?" Responses of 0-3 indicated low job stress, 4-6 indicated moderate job stress, and scores of 7 or greater indicated high job stress [Clark et al. 2011]. We asked employees questions about their perceptions of how approachable, trustworthy, and responsive the employer and union were about health and safety issues. We also asked about their perceptions of how effective the mist collectors and general ventilation systems were at removing contaminants from their work area.

In February 2016, we asked all cylinder head line, crank line, and long block assembly line employees to complete a self-administered written questionnaire. Using the questionnaire data, we created a variable that we called "asthma-like symptoms." Asthma-like symptoms were defined as one or more of the following:

- Current use of medicine for breathing problems or for asthma

- Wheezing or whistling in the chest at any time in the past month

- Awakening with a feeling of tightness in the chest at any time in the past month

- An attack of asthma in the past month

We also created a variable called work-related asthma-like symptoms. Work-related asthmalike symptoms were defined as any of the asthma-like symptoms that were reported to improve when away from work on days off or when on vacation. Work-related asthma-like symptoms were defined as having one or more of the following:

- Use of medicine for breathing problems or for asthma less often when away from work

- Wheezing or whistling in the chest in the past month that improved when away from work

- Awakening with a feeling of chest tightness in the past month that improved when away from work

- Attacks of asthma in the past month that were less frequent when away from work

\section{Data Analysis}

We analyzed the data using SAS statistical software version 9.3 and SPSS version 18. Because the data were not normal, we used the Wilcoxon Rank-Sum test to compare MWF air sampling levels for those working in the cylinder head, crankshaft, and long block assembly departments on the days of our air sampling. Using information reported on the questionnaire, we described participants' demographics, medical history, work hygiene, PPE usage, cleaning activities, perceptions of air quality, and perceptions of the employer's 
communication about and commitment to health and safety. We reported many of these descriptive statistics grouped by the department where the participants reported spending most of their time in the last month (i.e., cylinder head, crankshaft, or long block assembly). Using chi-square or Fisher's exact tests with their associated $P$ values, we compared the prevalence of work-related skin, nasal, and respiratory symptoms for participants in these departments. In addition, we calculated prevalence ratios with their associated $95 \%$ confidence intervals to compare work-related symptom prevalence for participants who frequently cleaned machines or parts to symptom prevalence for participants who never or sometimes cleaned machines or parts. These prevalence ratios were calculated for each type of substance used for cleaning (i.e., compressed air, coolant, or water). The prevalence ratio is the prevalence of the symptom in the more exposed group divided by the prevalence of the symptom in the comparison group. Therefore, a prevalence ratio of 1 would mean that symptom prevalence was the same for the two groups being compared. Confidence intervals for the prevalence ratio are based on our sample data and contain a range of values that we are $95 \%$ confident contain the population or "true" prevalence ratio. We can be confident of a difference in symptom prevalence for two groups if the confidence interval for the prevalence ratio does not include 1 . For this report we considered results with confidence intervals excluding 1 or results with $P$ values $<.05$ to be statistically significant. 


\section{Appendix C: Occupational Exposure Limits and Health Effects}

NIOSH investigators refer to mandatory (legally enforceable) and recommended OELs for chemical, physical, and biological agents when evaluating workplace hazards. OELs have been developed by federal agencies and safety and health organizations to prevent adverse health effects from workplace exposures. Generally, OELs suggest levels of exposure that most employees may be exposed to for up to 10 hours per day, 40 hours per week, for a working lifetime, without experiencing adverse health effects. However, not all employees will be protected if their exposures are maintained below these levels. Some may have adverse health effects because of individual susceptibility, a pre-existing medical condition, or a hypersensitivity (allergy). In addition, some hazardous substances act in combination with other exposures, with the general environment, or with medications or personal habits of the employee to produce adverse health effects. Most OELs address airborne exposures, but some substances can be absorbed directly through the skin and mucous membranes.

Most OELs are expressed as a time-weighted average (TWA) exposure. A TWA refers to the average exposure during a normal 8- to 10-hour workday. Some chemical substances and physical agents have recommended short term exposure limit or ceiling values. Unless otherwise noted, the short term exposure limit is a 15-minute TWA exposure. It should not be exceeded at any time during a workday. The ceiling limit should not be exceeded at any time.

In the United States, OELs have been established by federal agencies, professional organizations, state and local governments, and other entities. Some OELs are legally enforceable limits; others are recommendations.

- The U.S. Department of Labor OSHA PELs (29 CFR 1910 [general industry]; 29 CFR 1926 [construction industry]; and 29 CFR 1917 [maritime industry]) are legal limits. These limits are enforceable in workplaces covered under the Occupational Safety and Health Act of 1970.

- NIOSH RELs are recommendations based on a critical review of the scientific and technical information and the adequacy of methods to identify and control the hazard. NIOSH RELs are published in the NIOSH Pocket Guide to Chemical Hazards [NIOSH 2010]. NIOSH also recommends risk management practices (e.g., engineering controls, safe work practices, employee education/training, PPE, and exposure and medical monitoring) to minimize the risk of exposure and adverse health effects.

- Another set of OELs commonly used and cited in the United States is the ACGIH TLVs. The TLVs are developed by committee members of this professional organization from a review of the published, peer-reviewed literature. TLVs are not consensus standards. They are considered voluntary exposure guidelines for use by industrial hygienists and others trained in this discipline "to assist in the control of health hazards" [ACGIH 2017].

Outside the United States, OELs have been established by various agencies and organizations and include legal and recommended limits. The Institut für Arbeitsschutz der Deutschen 
Gesetzlichen Unfallversicherung (Institute for Occupational Safety and Health of the German Social Accident Insurance) maintains a database of international OELs from European Union member states, Canada (Québec), Japan, Switzerland, and the United States. The database, available at http://www.dguv.de/ifa/GESTIS/GESTIS-Internationale-Grenzwerte-fürchemische-Substanzen-limit-values-for-chemical-agents/index-2.jsp, contains international limits for more than 2,000 hazardous substances and is updated periodically.

OSHA requires an employer to furnish employees a place of employment free from recognized hazards that cause or are likely to cause death or serious physical harm [Occupational Safety and Health Act of 1970 (Public Law 91-596, sec. 5(a)(1))]. This is true in the absence of a specific OEL. It also is important to keep in mind that OELs may not reflect current health-based information.

When multiple OELs exist for a substance or agent, NIOSH investigators generally encourage employers to use the lowest OEL when making risk assessment and risk management decisions. NIOSH investigators also encourage use of the hierarchy of controls approach to eliminate or minimize workplace hazards. This includes, in order of preference, the use of (1) substitution or elimination of the hazardous agent, (2) engineering controls (e.g., local exhaust ventilation, process enclosure, dilution ventilation), (3) administrative controls (e.g., limiting time of exposure, employee training, work practice changes, medical surveillance), and (4) PPE (e.g., respiratory protection, gloves, eye protection, hearing protection). Control banding, a qualitative risk assessment and risk management tool, is a complementary approach to protecting employee health. Control banding focuses on how broad categories of risk should be managed. Information on control banding is available at http://www.cdc.gov/niosh/topics/ctrlbanding/. This approach can be applied in situations where OELs have not been established or can be used to supplement existing OELs.

\section{Metalworking Fluids}

MWFs are complex mixtures used to cool, lubricate, and remove metal chips from tools and parts during machining of metal stock. MWFs often contain other substances, including biocides, corrosion inhibitors, metal fines, tramp oils, and biological contaminants [Burton et al. 2012; NIOSH 1998a]. Inhalation of MWF aerosols may irritate the throat, nose, and lung and has been associated with chronic bronchitis, asthma, hypersensitivity pneumonitis, and worsening of pre-existing respiratory problems [Burton et al. 2012]. Hypersensitivity pneumonitis is a spectrum of granulomatous, interstitial lung diseases that occur after repeated inhalation and sensitization to one or more of a wide variety of microbial agents (bacteria, fungi, or amoebae), animal proteins, and low-molecular-weight chemical antigens [Centers for Disease Control and Prevention 1996; Zacharisen et al. 1998].

Skin contact with MWFs may cause allergic contact dermatitis or irritant contact dermatitis, depending on the chemical composition, additives and contaminants, type of metal being machined, and the exposed individual's tendency for developing allergies [WISHA 2001]. 
Synthetic, semisynthetic, and soluble oil MWFs are diluted with water, so bacteria may grow if an inadequate amount of biocide is present. The Health and Safety Executive in the United Kingdom states that well-maintained MWFs have bacterial concentrations below $10^{3}$ colony forming units $/ \mathrm{mL}$ of fluid [HSE 2006]. Concentrations between $10^{3}$ and $10^{6}$ colony forming units $/ \mathrm{mL}$ indicate reasonable control, and concentrations greater than $10^{6}$ colony forming units/ $\mathrm{mL}$ indicate poor control [HSE 2006]. The outer cell walls of Gram-negative bacteria may release lipopolysaccharide compounds called endotoxin when the bacteria die or multiply. Endotoxin is believed to cause adverse respiratory effects such as chronic bronchitis and asthma. In 2010, the Dutch Expert Committee on Occupational Safety recommended a healthbased OEL for airborne endotoxin of $90 \mathrm{EU} / \mathrm{m}^{3}$ [DECOS 2010]. Contaminated water in MWFs may also contain fungi. Some fungi may infect susceptible hosts, such as immune compromised persons, and some fungi may cause hypersensitivity pneumonitis. At this time, health data are insufficient to allow us to recommend a specific limit for fungal contamination in MWFs.

\section{Dicyclohexylamine}

DCHA may cause a skin allergy. If an allergy develops, very low future exposures can cause itching and a skin rash [Budavari 1996]. Skin contact can severely irritate and burn the skin [Hawley 1977]. Breathing DCHA can irritate the nose, throat, and lungs causing coughing, wheezing and/or shortness of breath [IPCS 2012]. High levels of exposure can cause nausea, vomiting, restlessness, and drowsiness [Gosselin et al. 1976]. In addition, DCHA can be absorbed through the skin [IPCS 2012]. Although no OELs for DCHA exposure exist in the United States, Germany has established an exposure limit of $0.7 \mathrm{ppm}$ for an 8-hour TWA. Furthermore, the Registration, Evaluation, Authorisation, and Restriction of Chemicals legislation, developed by the European Union, has established a derived no effect level of $0.353 \mathrm{mg} / \mathrm{m}^{3}$ [OECD 2015]. 


\section{Appendix D: Contact Dermatitis}

Contact dermatitis makes up $90 \%$ to $95 \%$ of all occupational skin diseases [Ingber and Merims 2004; Lushniak 2004]. Contact dermatitis, both irritant and allergic, is an inflammatory skin condition caused by skin contact with agents such as chemical irritants (irritant contact dermatitis) or allergens (allergic contact dermatitis). Irritant contact dermatitis is skin inflammation due to direct cell damage from a chemical or physical agent, while allergic contact dermatitis is a delayed immune reaction. Over 57,000 chemicals are reported to cause skin irritation, but only 3,700 chemicals are known skin allergens [Belsito 2005]. Usually, only a small percentage of people are susceptible to skin allergens.

In contact dermatitis, the skin initially turns red and can develop bumps and small, oozing blisters. After several days, crusts and scales form. Stinging, burning, and itching often occur. With no further contact with the agent, the dermatitis usually disappears in 1 to 3 weeks. With chronic exposure, deep fissures, scaling, and darkening of the skin can occur. Exposed areas of the skin, such as hands and forearms, have the greatest contact with irritants or allergens and are most commonly affected. Over $80 \%$ of occupational contact dermatitis involves the hands [Belsito 2005; Flyvholm et al. 2007; Warshaw et al. 2003]. If the agent gets on clothing, it can bring on dermatitis at areas of greatest contact, such as thighs, upper back, armpits, and feet. Dusts can produce dermatitis at areas where the dust accumulates and is held in contact with the skin, such as under the collar and belt line, at the tops of socks or shoes, and in skin creases, such as inside elbows and behind knees. Mists can produce dermatitis on the face and neck. Irritants and allergens can be transferred to distant areas of the body, such as the trunk or genitalia, by unwashed hands or from areas of accumulation, such as under rings or in finger webs.

It is often impossible to clinically distinguish irritant contact from allergic contact dermatitis, as both can have a similar appearance and both can result in an acute, subacute, or chronic condition. Irritant contact dermatitis can be caused by many factors. The most common skin irritant at work is wet work, defined as exposure of skin to liquid for more than 2 hours per day, use of occlusive gloves for more than 2 hours per day, or frequent hand washing [Chew and Maibach 2003; Slodownik et al. 2008]. Other common causes of irritant contact dermatitis include soaps and detergents, solvents, food products, cleaning agents, plastics and resins, petroleum products and lubricants, metals, and machine oils and coolants [Chew and Maibach 2003; Slodownik et al. 2008]. Frictional irritant contact dermatitis can be caused by low humidity, heat, paper, tools, metals, fabrics, plastics, fibrous glass and other particulate dusts, and cardboard, among other causes [McMullen and Gawkrodger 2006; MorrisJones et al. 2002]. Causes of allergic contact dermatitis include plants such as poison ivy, metallic salts, germicides, plastic resins, rubber additives, and fragrances [Mathias 1990]. In patients with occupational contact dermatitis who were skin-patch tested, the most common relevant allergens included thiuram mix, carba mix, bacitracin, methyldibromo glutaronitrile/ phenoxyethanol, formaldehyde, glutaraldehyde, methylmethacrylate, nickel, cobalt, and chromium [Warshaw et al. 2007, 2008]. 
Studies on the prognosis of occupational contact dermatitis stress the importance of primary prevention. One study found that $32 \%$ of 124 surveyed patients had severe hand dermatitis 5 years after they were initially diagnosed with irritant hand dermatitis. Severity was measured by self-reported frequency of relapses, frequency of dermatologist visits, and use of topical corticosteroids [Jungbauer et al. 2004]. Another study found that $25 \%$ of 540 surveyed patients had persistently severe or aggravated symptoms a year after initial diagnosis of occupational hand dermatitis. Poor prognosis was associated with the presence of atopic dermatitis and being 25 years of age or older. Prognosis was not affected by whether the dermatitis was irritant or allergic. Those with severe occupational hand dermatitis at baseline had a higher risk of taking sick leave and job loss in the following year than those with mild cases. The study found no significant improvement in the disease after the change of job [Cvetkovski et al. 2006]. Widespread hand dermatitis on initial examination was found to be the greatest factor for a poor long-term prognosis in a third study [Meding et al. 2005]. In addition, many skin disorders, including contact dermatitis, have been shown to have a significant impact on quality of life [Cvetkovski et al. 2005; Fowler et al. 2006; Kadyk et al. 2003; Lan et al. 2008].

\section{Preventing Contact Dermatitis}

Avoiding irritants and allergens, in addition to wet work, is the first step in dermatitis prevention. Liberal use of skin moisturizers helps to prevent contact dermatitis by maintaining a healthy skin barrier, and also helps to repair this barrier if it has been compromised [Chew and Maibach 2003]. The following list provides strategies in the prevention of occupational contact dermatitis:

- Identifying irritants and allergens

- Substituting chemicals that are less irritating or allergenic

- Establishing engineering controls to reduce exposure

- Emphasizing personal and occupational hygiene

- Establishing educational programs to increase awareness in the workplace

- Using PPE, such as gloves and special clothing [NIOSH 1988]

Chemical changes in industrial materials have been beneficial. For example, the addition of ferrous sulfate to cement to reduce the hexavalent chromium content has been effective in reducing occupational allergic contact dermatitis in Europe [Goh and Gan 1996]. Avoiding the use of formaldehyde-releasing biocides in MWF will likely reduce contact dermatitis among machinists [Aalto-Korte et al. 2008]. Protective gloves can reduce or eliminate skin exposure to hazardous substances if used correctly but may actually cause or worsen hand dermatitis (by permeation and penetration) if selected poorly and used improperly (by contamination) [Foo et al. 2006]. The use of PPE may occlude irritants or allergens next to the skin, and PPE components may directly irritate the skin. Therefore, the correct use of PPE is at least as important as the correct selection of materials [Kwon et al. 2006]. Similarly, the excessive pursuit of personal hygiene in the workplace may actually lead to misuse of soaps and detergents and cause irritant contact dermatitis. Proper hand washing methods and 
adequate moisturizing are valuable in preventing contact dermatitis [Warshaw 2003]. The effectiveness of barrier creams is controversial because data on the protective nature of these topical products during actual working conditions involving high-risk exposures are limited. Educating the workforce about skin care, exposures, and PPE use is an especially important measure in the prevention of occupational contact dermatitis [Loffler et al. 2006; Schwanitz et al. 2003; Weisshaar et al. 2006]. The following list provides tips on proper hand washing [Warshaw et al. 2003]:

- Avoid hot water; use lukewarm or cool water instead.

- Use mild cleansers without perfume, coloring, or antibacterial agents.

- Pat hands dry, especially between fingers.

- Apply skin moisturizer generously after hand washing and repeat throughout the day.

- Avoid rubbing, scrubbing, the use of washcloths, and the overuse of soap and water.

This additional list provides tips for the workplace [Warshaw et al. 2003]:

- Remove rings before work.

- Wear protective gloves in cold weather and for dusty work.

- Wear tight-fitting leather gloves for frictional exposures.

- When performing wet work, wear cotton gloves under vinyl or other nonlatex gloves.

- Avoid immersing hands; use running water if possible. 


\section{References}

ACGIH [2017]. 2017 TLVs ${ }^{\circledR}$ and BEIs ${ }^{\circledR}$ : threshold limit values for chemical substances and physical agents and biological exposure indices. Cincinnati, OH: American Conference of Governmental Industrial Hygienists.

Aalto-Korte K, Kuuliala O, Suuronen K, Alanko K [2008]. Occupational contact allergy to formaldehyde and formaldehyde releasers. Contact Dermatitis 59(5):280-289, http://dx.doi.org/10.1111/j.1600-0536.2008.01422.x.

Apfelbacher CJ, Radulescu M, Diepgen TL, Funke U [2008]. Occurrence and prognosis of hand eczema in the car industry: results from the PACO follow-up study (PACO II). Contact Dermatitis 58(6):322-329, http://dx.doi.org/10.1111/j.1600-0536.2008.01329.x.

Bantz SK, Zhu Z, Zheng T [2014]. The atopic march: progression from atopic dermatitis to allergic rhinitis and asthma. J Clin Cell Immunol 5:202, http://dx.doi.org/10.4172/2155-9899.1000202.

Belsito DV [2005]. Occupational contact dermatitis: etiology, prevalence, and resultant impairment/disability. J Am Acad Dermatol 53(2):303-313, http://dx.doi.org/10.1016/j.jaad.2005.02.045.

Berndt U, Hinnen U, Iliev D, Elsner P [2000]. Hand eczema in metalworker trainees - an analysis of risk factors. Contact Dermatitis 43(6):327-332.

Budavari S, ed. [1996]. The Merck Index - an encyclopedia of chemicals, drugs, and biologicals. Whitehouse Station, NJ: Merck and Co., Inc., p. 524.

Burton CM, Crook B, Scaife H, Evans GS, Barber CM [2012]. Systematic review of respiratory outbreaks associated with exposure to water based metalworking fluids. Ann Occup Hyg 56(4):374-388, http://dx.doi.org/10.1093/annhyg/mer121. Advance online publication.

Centers for Disease Control and Prevention [1996]. Biopsy-confirmed hypersensitivity pneumonitis in automobile production workers exposed to metalworking fluids-Michigan, 1994-1995. MMWR 45(28):606-610.

CFR. Code of Federal Regulations. Washington, DC: U.S. Government Printing Office, Office of the Federal Register.

Chew AI, Maibach HI [2003]. Occupational issues of irritant contact dermatitis. Int Arch Occup Environ Health 76(5):339-346, http://dx.doi.org/10.1007/s00420-002-0419-0.

Clark MM, Warren BA, Hagen PT, Johnson BD, Jenkins SM, Werneburg BL, Olsen KD [2011]. Stress level, health behaviors, and quality of life in employees joining a wellness center. Am J Health Promot 26(1):21-25, http://dx.doi.org/10.4278/ajhp.090821-QUAN-272. 
Cvetkovski RS, Rothman KJ, Olsen J, Mathiesen B, Iversen L, Johansen JD, Agner T [2005]. Relation between diagnoses on severity, sick leave and loss of job among patients with occupational hand eczema. Br J Dermatol 152(1):93-98, http://dx.doi.org/10.1111/j.1365-2133.2005.06415.x.

Cvetkovski RS, Zachariae R, Jensen H, Olsen J, Johansen JD, Agner T [2006]. Prognosis of occupational hand eczema. Arch Dermatol 142(3):305-311, https://dx.doi.org/10.1001/archderm.142.3.305.

DECOS [2010]. Endotoxins: health-based recommended occupational exposure limit. The Hague: Health Council of the Netherlands, Dutch Expert Committee on Occupational Safety, http://www.gezondheidsraad.nl/sites/default/files/201004OSH.pdf.

Flyvholm MA, Bach B, Rose M, Jepsen KF [2007]. Self-reported hand eczema in a hospital population. Contact Dermatitis 57(2):110-115, http://dx.doi.org/10.1111/j.1600-0536.2007.01134.x.

Foo CC, Goon AT, Leow YH, Goh CL [2006]. Adverse skin reactions to personal protective equipment against severe acute respiratory syndrome-a descriptive study in Singapore. Contact Dermatitis 55(5):291-294, http://dx.doi.org/10.1111/j.1600-0536.2006.00953.x.

Fowler JF, Ghosh A, Sung J, Emani S, Chang J, Den E, Thorn D, Person J, Duh MS [2006]. Impact of chronic hand dermatitis on quality of life, work productivity, activity impairment, and medical costs. J Am Acad Dermatol 54(3):448-457, http://dx.doi.org/10.1016/j.jaad.2005.11.1053.

Goh CL, Gan SL [1996]. Change in cement manufacturing process, a cause for decline in chromate allergy? Contact Dermatitis 34(1):51-54, http://dx.doi.org/10.1111/j.1600-0536.1996.tb02112.x.

Grassi M, Rezzani C, Biino G, Marinoni A [2003]. Asthma-like symptoms assessment through ECRHS screening questionnaire scoring. J Clin Epidemiol 56(3):238-247, http://dx.doi.org/10.1016/S0895-4356(02)00613-3.

Gosselin RE, Hodge HC, Smith RP, Gleason MN [1976]. Clinical toxicology of commercial products. 4th ed. Baltimore, MD: Williams and Wilkins, p. II-139.

Guerra S, Sherrill DL, Martinez FD, Barbee RA [2002]. Rhinitis as an independent risk factor for adult-onset asthma. J Allergy Clin Immunol 109(3):419-425, http://dx.doi.org/10.1067/mai.2002.121701.

Hawley GG, ed. [1977]. The condensed chemical dictionary. 9th ed. New York: Van Nostrand Reinhold Co., p. 283.

Hornung RW, Reed LD [1990]. Estimation of average concentration in the presence of nondetectable values. AOEH 5(1):46-51, https://doi.org/10.1080/1047322X.1990.10389587. 
HSE (Health and Safety Executive) [2006]. Managing sumps and bacterial contamination: control approach 4. COSHH essentials for machining with metalworking fluids, http://www.hse.gov.uk/pubns/guidance/mw05.pdf.

Ingber A, Merims S [2004]. The validity of the Mathias criteria for establishing occupational causation and aggravation of contact dermatitis. Contact Dermatitis 51(1):9-12, http://dx.doi.org/10.1111/j.0105-1873.2004.00273.x.

IPCS [2012]. International Programme on Chemical Safety. Chemical Safety Information from International Organizations, http://www.inchem.org/documents/icsc/icsc/eics1339.htm.

Jungbauer FH, van der Vleuten P, Groothoff JW, Coenraads PJ [2004]. Irritant hand dermatitis: severity of disease, occupational exposure to skin irritants and preventive measures 5 years after initial diagnosis. Contact Dermatitis 50(4):245-251, http://dx.doi.org/10.1111/j.0105-1873.2004.00347.x.

Kadyk DL, McCarter K, Achen F, Belsito DV [2003]. Quality of life in patients with allergic contact dermatitis. J Am Acad Dermatol 49(6):1037-1048, http://dx.doi.org/10.1016/S0190-9622(03)02112-1.

Kwon S, Campbell LS, Zirwas MJ [2006]. Role of protective gloves in the causation and treatment of occupational irritant contact dermatitis. J Am Acad Dermatol 55(5):891-896, http://dx.doi.org/10.1016/j.jaad.2006.05.037.

Lan CC, Feng WW, Lu YW, Wu CS, Hung ST, Hsu HY, Yu HS, Ko YC, Lee CH, Yang YH, Chen GS [2008]. Hand eczema among University Hospital nursing staff: identification of high-risk sector and impact on quality of life. Contact Dermatitis 59(5):301-306, http://dx.doi.org/10.1111/j.1600-0536.2008.01439.x.

Lillienberg L, Andersson EM, Järvholm B, Toren K [2010]. Respiratory symptoms and exposure-response relations in workers exposed to metalworking fluid aerosols. Ann Occup Hyg 54(4):403-411, http://dx.doi.org/10.1093/annhyg/meq009.

Loffler H, Bruckner T, Diepgen T, Effendy I [2006]. Primary prevention in health care employees: a prospective intervention study with a 3-year training period. Contact Dermatitis 54(4):202-209, http://dx.doi.org/10.1111/j.0105-1873.2006.00825.x.

Lushniak BD [2004]. Occupational contact dermatitis. Dermatol Ther 17(3):272-277, http://dx.doi.org/10.1111/j.1396-0296.2004.04032.x.

McMullen E, Gawkrodger DJ [2006]. Physical friction is under-recognized as an irritant that can cause or contribute to contact dermatitis. Br J Dermatol 154(1):154-156, http://dx.doi.org/10.1111/j.1365-2133.2005.06957.x.

Mathias CGT [1990]. Prevention of occupational contact dermatitis. J Am Acad Dermatol 23(4 Pt 1):742-748, http://dx.doi.org/10.1016/0190-9622(90)70284-O. 
Meding B, Wrangsjo K, Jarvholm B [2005]. Fifteen-year follow-up of hand eczema: predictive factors. J Invest Dermatol 124(5):893-897, http://dx.doi.org/10.1111/j.0022-202X.2005.23723.x.

Morris-Jones R, Robertson SJ, Ross JS, White IR, McFadden JP, Rycroft RJ [2002]. Dermatitis caused by physical irritants. Br J Dermatol 147(2):270-275, http://dx.doi.org/10.1046/j.1365-2133.2002.04852.x.

NIOSH [1988]. Proposed national strategy for the prevention of leading work-related diseases and injuries: dermatological conditions. Cincinnati, OH: U.S. Department of Health and Human Services, Centers for Disease Control and Prevention, National Institute for Occupational Safety and Health, DHHS (NIOSH) Publication No. 89-136.

NIOSH [1998a]. Criteria for a recommended standard: occupational exposure to metalworking fluids. Cincinnati, OH: U.S. Department of Health and Human Services, Centers for Disease Control and Prevention, National Institute for Occupational Safety and Health, DHHS (NIOSH) Publication No. 98-102.

NIOSH [1998b]. What you need to know about occupational exposure to metalworking fluids. Cincinnati, OH: U.S. Department of Health and Human Services, Centers for Disease Control and Prevention, National Institute for Occupational Safety and Health, DHHS (NIOSH) Publication No. 98-116.

NIOSH [2010]. NIOSH pocket guide to chemical hazards. Cincinnati, OH: U.S. Department of Health and Human Services, Centers for Disease Control and Prevention, National Institute for Occupational Safety and Health, DHHS (NIOSH) Publication No. 2010-168c, http://www.cdc.gov/niosh/npg/.

NIOSH [2013]. Metalworking fluids. Cincinnati, OH: U.S. Department of Health and Human Services, Centers for Disease Control and Prevention, National Institute for Occupational Safety and Health, https://www.cdc.gov/niosh/topics/metalworking/.

NIOSH [2016]. Investigation of dermal and respiratory exposures to metalworking fluids at an automotive parts manufacturer. By Harney JM and Tapp L. Cincinnati, OH: U.S. Department of Health and Human Services, Centers for Disease Control and Prevention, National Institute for Occupational Safety and Health, NIOSH Health Hazard Evaluation Report 2013-0075-3264, https://www.cdc.gov/niosh/hhe/reports/pdfs/2013-0075-3264.pdf.

NIOSH [2018]. NIOSH manual of analytical methods (NMAM). 5th ed. O'Connor PF, Ashley K, eds. Cincinnati, OH: U.S. Department of Health and Human Services, Centers for Disease Control and Prevention, National Institute for Occupational Safety and Health, DHHS (NIOSH) Publication No. 2014-151, http://www.cdc.gov/niosh/nmam.

OECD [2015]. eChemPortal. The global portal to information on chemical substances. http://www.echemportal.org/echemportal/index?pageID $=0 \&$ request locale $=$ en.

OSHA [2000]. Metalworking fluids: safety and health best practices manual. Occupational Safety and Health Administration, United States Department of Labor; https://www.osha.gov/SLTC/metalworkingfluids/metalworkingfluids manual.html. 
Park DU, Jin KW, Koh DH, Kim BK, Kim KS, Park DY [2008]. Association between use of synthetic metalworking fluid and risk of developing rhinitis-related symptoms in an automotive ring manufacturing plant. J Occup Health 50(2):212-220, http://dx.doi.org/10.1539/joh.O7006.

Schwanitz HJ, Riel U, Schlesinger T, Bock M, Skudlik C, Wulfhorst B [2003]. Skin care management: educational aspects. Int Arch Occup Environ Health 76(5):374-381, http://dx.doi.org/10.1007/s00420-002-0428-z.

Slodownik D, Lee A, Nixon R [2008]. Irritant contact dermatitis: a review. Australas J Dermatol 49(1):1-9, http://dx.doi.org/10.1111/j.1440-0960.2007.00409.x.

Susitaival P, Flyvholm MA, Meding B, Kanerva L, Lindberg M, Svensson A, Olafsson JH [2003]. Nordic Occupational Skin Questionnaire (NOSQ-2002): a new tool for surveying occupational skin diseases and exposure. Contact Dermatitis 49(2):70-76.

Vecchio-Sudus AM, Griffiths S [2004]. Marketing strategies for enhancing safety culture. Safety Science 42(7):601-619.

Warshaw E, Lee G, Storrs FJ [2003]. Hand dermatitis: a review of clinical features, therapeutic options and long-term outcomes. Am J Contact Dermat 14(3):119-137.

Warshaw EM, Ahmed RL, Belsito DV, DeLeo VA, Fowler JF, Maibach HI, Marks JG, Mathias CG, Pratt MD, Rietschel RL, Sasseville D, Storrs FJ, Taylor JS, Zug KA [2007]. Contact dermatitis of the hands: cross-sectional analyses of North American Contact Dermatitis Group Data, 1994-2004. J Am Acad Dermatol 57(2):301-314, http://dx.doi.org/10.1016/j.jaad.2007.04.016.

Warshaw EM, Schram SE, Maibach HI, Belsito DV, Marks JG, Fowler JF, Rietschel RL, Taylor JS, Mathias CG, DeLeo VA, Zug KA, Sasseville D, Storrs FJ, Pratt MD [2008]. Occupation-related contact dermatitis in North American health care workers referred for patch testing: cross-sectional data, 1998-2004. Dermatitis 19(5):261-274, http://dx.doi/10.2310/6620.2008.07059.

Weisshaar E, Radulescu M, Bock M, Albrecht U, Diepgen TL [2006]. Educational and dermatological aspects of secondary individual prevention in healthcare workers. Contact Dermatitis 54(5):254-260, http://dx.doi.org/10.1111/j.0105-1873.2006.00811.x.

WISHA [2001]. Preventing occupational dermatitis. Olympia, WA: Washington State Department of Labor and Industries, Safety \& Health Assessment \& Research for Prevention (SHARP) Publication No. 56-01-1999.

Zacharisen MC, Kadambi AR, Schlueter DP, Kurup VP, Shack JB, Fox JL, Anderson HA, Fink JN [1998]. The spectrum of respiratory disease associated with exposure to metalworking fluids. J Occup Environ Med 40(7):640-647. 
Keywords: North American Industry Classification System (NAICS) 336310 (Motor

Vehicle Gasoline Engine and Engine Parts Manufacturing), Michigan, Metal Working Fluid, Chemicals, MWF, Rashes, Skin, Respiratory, Dicyclohexylamine, DCHA, Metal Machining 
This page left intentionally blank 
The Health Hazard Evaluation Program investigates possible health hazards in the workplace under the authority of the Occupational Safety and Health Act of 1970 (29 U.S.C. § 669(a) (6)). The Health Hazard Evaluation Program also provides, upon request, technical assistance to federal, state, and local agencies to investigate occupational health hazards and to prevent occupational disease or injury. Regulations guiding the Program can be found in Title 42, Code of Federal Regulations, Part 85; Requests for Health Hazard Evaluations (42 CFR Part 85).

\section{Disclaimer}

The recommendations in this report are made on the basis of the findings at the workplace evaluated and may not be applicable to other workplaces.

Mention of any company or product in this report does not constitute endorsement by NIOSH.

Citations to Web sites external to NIOSH do not constitute NIOSH endorsement of the sponsoring organizations or their programs or products. NIOSH is not responsible for the content of these Web sites. All Web addresses referenced in this document were accessible as of the publication date.

\section{Acknowledgments}

Analytical Support: Bureau Veritas North America (Maxxam Analytics)

Desktop Publisher: Shawna Watts

Editor: Ellen Galloway

Industrial Hygiene Field Assistance: Scott Brueck, Josh Harney, Donnie Booher

Logistics: Donnie Booher, Kevin Moore

Medical Field Assistance: Rini Matthews, Chia-ping Su, David Boren

\section{Availability of Report}

Copies of this report have been sent to the employer, union, and employees at the facility.

The state and local health department and the Occupational Safety and Health Administration

Regional Office have also received a copy. This report is not copyrighted and may be freely reproduced.

\section{Recommended citation for this report:}

NIOSH [2018]. Evaluation of metalworking fluid exposure, dermatitis, respiratory symptoms, and psychosocial factors in an engine machining plant. By Beaucham $\mathrm{C}$, Tapp L, Wiegand D, Couch J, Mueller C. Cincinnati, OH: U.S. Department of Health and Human Services, Centers for Disease Control and Prevention, National Institute for Occupational Safety and Health, Health Hazard Evaluation Report 2015-0070-3304, https:/www.cdc.gov/niosh/hhe/reports/pdfs/2015-0070-3304.pdf. 
Delivering on the Nation's promise:

Promoting productive workplaces through safety and health research

To receive NIOSH documents or more information about occupational safety and health topics, please contact NIOSH:

Telephone: 1-800-CDC-INFO (1-800-232-4636)

TTY: 1-888-232-6348

CDC INFO: www.cdc.gov/info

or visit the NIOSH Web site at www.cdc.gov/niosh

For a monthly update on news at $\mathrm{NIOSH}$, subscribe to

$\mathrm{NIOSH}$ eNews by visiting www.cdc.gov/niosh/eNews. 